\title{
Validation of digital elevation models (DEMs) and comparison of geomorphic metrics on the southern Central Andean Plateau
}

\author{
Benjamin Purinton and Bodo Bookhagen \\ Institute of Earth and Environmental Science, Universität Potsdam, Potsdam, Germany \\ Correspondence to: Benjamin Purinton (purinton@uni-potsdam.de)
}

Received: 17 January 2017 - Discussion started: 1 February 2017

Revised: 28 March 2017 - Accepted: 28 March 2017 - Published: 13 April 2017

Abstract. In this study, we validate and compare elevation accuracy and geomorphic metrics of satellite-derived digital elevation models (DEMs) on the southern Central Andean Plateau. The plateau has an average elevation of $3.7 \mathrm{~km}$ and is characterized by diverse topography and relief, lack of vegetation, and clear skies that create ideal conditions for remote sensing. At $30 \mathrm{~m}$ resolution, SRTM-C, ASTER GDEM2, stacked ASTER L1A stereopair DEM, ALOS World 3D, and TanDEM-X have been analyzed. The higher-resolution datasets include $12 \mathrm{~m}$ TanDEM-X, $10 \mathrm{~m}$ single-CoSSC TerraSAR-X/TanDEM-X DEMs, and $5 \mathrm{~m}$ ALOS World 3D. These DEMs are state of the art for optical (ASTER and ALOS) and radar (SRTM-C and TanDEM-X) spaceborne sensors.

We assessed vertical accuracy by comparing standard deviations of the DEM elevation versus 307509 differential GPS measurements across $4000 \mathrm{~m}$ of elevation. For the $30 \mathrm{~m}$ DEMs, the ASTER datasets had the highest vertical standard deviation at $>6.5 \mathrm{~m}$, whereas the SRTM-C, ALOS World 3D, and TanDEM-X were all $<3.5 \mathrm{~m}$. Higher-resolution DEMs generally had lower uncertainty, with both the $12 \mathrm{~m}$ TanDEM-X and $5 \mathrm{~m}$ ALOS World $3 \mathrm{D}$ having $<2 \mathrm{~m}$ vertical standard deviation. Analysis of vertical uncertainty with respect to terrain elevation, slope, and aspect revealed the low uncertainty across these attributes for SRTM-C (30 m), TanDEM-X $(12-30 \mathrm{~m})$, and ALOS World 3D (5-30 m). Single-CoSSC TerraSAR-X/TanDEM-X $10 \mathrm{~m}$ DEMs and the $30 \mathrm{~m}$ ASTER GDEM2 displayed slight aspect biases, which were removed in their stacked counterparts (TanDEM-X and ASTER Stack).

Based on low vertical standard deviations and visual inspection alongside optical satellite data, we selected the $30 \mathrm{~m}$ SRTM-C, 12-30 m TanDEM-X, $10 \mathrm{~m}$ single-CoSSC TerraSAR-X/TanDEM-X, and $5 \mathrm{~m}$ ALOS World 3D for geomorphic metric comparison in a $66 \mathrm{~km}^{2}$ catchment with a distinct river knickpoint. Consistent $m / n$ values were found using chi plot channel profile analysis, regardless of DEM type and spatial resolution. Slope, curvature, and drainage area were calculated and plotting schemes were used to assess basin-wide differences in the hillslope-to-valley transition related to the knickpoint. While slope and hillslope length measurements vary little between datasets, curvature displays higher magnitude measurements with fining resolution. This is especially true for the optical $5 \mathrm{~m}$ ALOS World 3D DEM, which demonstrated high-frequency noise in 2-8 pixel steps through a Fourier frequency analysis. The improvements in accurate space-radar DEMs (e.g., TanDEM-X) for geomorphometry are promising, but airborne or terrestrial data are still necessary for meter-scale analysis. 


\section{Introduction}

Digital elevation models (DEMs) provide hydrologists and geomorphologists with powerful tools to explore the linkages between fundamental geomorphic processes and landforms. Previously, DEMs have been used to test hypotheses of landscape evolution at local and regional scales using geomorphic metrics (e.g., Howard et al., 1994; Burbank et al., 1996; Whipple and Tucker, 1999; Montgomery et al., 2001; Dietrich et al., 2003; Roering et al., 2007). Modern geomorphologists use the quantitative subdiscipline of geomorphometry (Pike et al., 2009; Wilson, 2012; Sofia et al., 2016) to explore how tectonic, climatic, and lithologic signals can be inferred from DEMs (e.g., Snyder et al., 2000; Wobus et al., 2006; DiBiase et al., 2010; Bookhagen and Strecker, 2012; Kirby and Whipple, 2012; Scherler et al., 2015; Clubb et al., 2016; Olen et al., 2016), but questions remain to what extent transient responses can be recorded in landscape morphology (e.g., DiBiase et al., 2012) and how channel networks and hillslopes can independently act as records of basin transience (e.g., Ouimet et al., 2009; Hurst et al., 2012; Clubb et al., 2016; Forte et al., 2016). Such studies rely on accurate DEMs for the calculation of geomorphic metrics (e.g., slope and curvature) and extraction of geomorphic features (e.g., channels, hillslopes, hilltops). In spite of this, DEM elevation error reporting (Fisher and Tate, 2006; Reuter et al., 2009) - often carried out with limited control data - only accounts for absolute pixel elevation accuracy and does not include higher-order DEM derivatives (e.g., slope and curvature), geomorphic metrics, or landscape features of interest to geomorphologists. This problem is especially acute given that relatively small elevation errors will propagate and grow in the first (slope) and second (curvature) derivatives, potentially obscuring geomorphometric results (e.g., Wechsler, 2007).

Remotely sensed DEMs - referred to throughout this study as DEMs, as opposed to the often-used term digital terrain model (DTM) for bare-earth models with vegetation and structures removed - are generated from data that are originally distorted through sensor, terrain, and atmospheric conditions, leading to misrepresentations (error) in the final product (Smith and Sandwell, 2003; Fisher and Tate, 2006; Nuth and Kääb, 2011). These datasets are commonly received in gridded format - rather than point cloud, triangulated irregular network (TIN), or other recently developed adaptive formats (e.g., Liu et al., 2014) - resulting in a defined measurement interval (grid resolution) that may oversimplify fine landscape variability. Thus, the geomorphic scales of interest must be taken into consideration when selecting the appropriate DEM (e.g., Hengl, 2006). For instance, while channel profiles over long reaches are readily analyzed on $90 \mathrm{~m}$ resolution data, hillslopes with considerably smaller extents require higher $1-30 \mathrm{~m}$ resolution data capable of identifying individual hillslopes and ridges (Grieve et al., 2016a, b, c). Furthermore, DEM biases spe- cific to a given sensor should be considered prior to analysis, especially when using satellite-derived DEMs in steep topography (e.g., Paul and Haeberli, 2008; Nuth and Kääb, 2011; Pipaud et al., 2015).

Since the release of the first global DEM by the United States Geological Survey (USGS) in 1996 (GTOPO30) at a resolution of $30 \operatorname{arcsec}(\sim 1 \mathrm{~km})$, advances in remote sensing technology - particularly satellite observation - and processing capabilities have steadily improved the accuracy and increased the resolution of DEMs. The 2003 public release of the $90 \mathrm{~m}$ Shuttle Radar Topography Mission (SRTM) DEM with coverage from $56^{\circ} \mathrm{S}$ to $60^{\circ} \mathrm{N}$ (Farr et al., 2007) ushered in a new age of near-global digital topographic analysis (Wilson, 2012). With the 2009 release of the $30 \mathrm{~m}$ Advanced Spaceborne Thermal Emission and Reflection Radiometer Global DEM (ASTER GDEM; METI/NASA/USGS, 2009), and more recent releases of the improved ASTER GDEM version 2 (ASTER GDEM2; Tachikawa et al., 2011), SRTM C-band $30 \mathrm{~m}$ (SRTM-C), and up-sampled Advanced Land Observing Satellite (ALOS) World 3D 30 m (AW3D30), geomorphologists now have open access to many $30 \mathrm{~m}$ nearglobal DEMs. In addition to these public $30 \mathrm{~m}$ datasets, higher-resolution $(<15 \mathrm{~m})$ DEMs from a variety of satellite sources are becoming increasingly available through commercial purchase or research agreements as edited products (e.g., ALOS World 3D and TanDEM-X WorldDEM), optical pairs for stereogrammetric processing (e.g., ALOS Panchromatic Remote-sensing Instrument for Stereo Mapping, or PRISM), and radar scenes for interferometric processing (e.g., TerraSAR-X/TanDEM-X).

The SRTM-C and ASTER GDEM2 have reported vertical accuracies of $\sim 5-20 \mathrm{~m}$ depending on terrain characteristics (e.g., Mukherjee et al., 2013; Rexer and Hirt, 2014), with some biases reported related to slope and aspect of the terrain (e.g., Berthier et al., 2006; Nuth and Kääb et al., 2011; Shortridge and Messina, 2011). While these accuracies allow long-term (decadal) tracking of glacial elevation changes (e.g., Racoviteanu et al., 2007; Paul and Haeberli, 2008), higher-resolution local DEMs from optical and radar sources have proven more accurate $(<5 \mathrm{~m}$ vertical error) than these global products for glacial studies in steep terrain, particularly on shorter timescales (e.g., Berthier et al., 2007; Berthier and Toutin, 2008; Jaber et al., 2013; Neckel et al., 2013; Pandey and Venkataraman, 2013; Holzer et al., 2015; Rankl and Braun, 2016; Neelmeijer et al., 2017). However, to date no studies have assessed the accuracy of the current generation of sub-15 m, satellite-derived DEMs with regards to geomorphometry. These measurements, unlike glacial studies, rely on the derivatives of elevation (e.g., slope and curvature) and their spatial context, not absolute or relative height changes. Furthermore, glacial studies are typically conducted on lower-slope terrain and compare areawide measurements, allowing some uncertainties to average out. Conversely, geomorphic studies examining channels and hillslopes in steeper terrain may be more impacted by 
remote-sensing errors and artifacts (e.g., from shadowing, sensor angle, foreshortening), and geomorphic metrics like slope and curvature rely on the accuracy of nearby pixels, for example within a $3 \times 3$ pixel moving window.

The application of light detection and ranging (lidar) by ground and aerial methods is often used to generate meterto sub-meter-scale elevation point clouds and gridded DEM datasets at smaller areal extents than satellite-derived DEMs (e.g., Passalacqua et al., 2015). Lidar has revolutionized geomorphology with more accurate representations of the land surface and has led to new insights and discoveries in the realm of mass and energy transport laws (Dietrich et al., 2003; Roering et al., 2007), channel initiation (Passalacqua et al., 2010a, b), surface flow routing (Shelef and Hilley, 2013), erosion (Perroy et al., 2010), and landslide and fault scarp mapping (e.g., Roering et al., 2013; Tarolli, 2014). While coarser DEMs have proven useful in exploring mountain belt hypsometry and linkages between climate, erosion, and tectonics at basin or regional scales (e.g., Montgomery et al., 2001; DiBiase et al., 2010; Bookhagen and Strecker, 2012), their utility in analyzing process-level geomorphology and assessing critical hillslope parameters is limited and lidar is often deemed necessary (Roering et al., 2013; Tarolli, 2014; Passalacqua et al., 2015). Despite this, the limited spatial extent $\left(\sim 1 \mathrm{~km}^{2}\right)$ and high effort and cost of obtaining lidar are prohibitive factors to its application at basin or regional scales $\left(10-1000 \mathrm{~km}^{2}\right)$.

Previous studies examining the effect of DEM resolution on geomorphic metrics and features have primarily used resampled or re-gridded lidar data (e.g., Tarolli and Tarboton, 2006; Tarolli and Dalla Fontana, 2009; Grieve et al., 2016c). Here we are interested not in high-quality resampled data, but rather data at their original resolution collected from different sensors, without any higher-resolution information from resampling. Advances in sub-15 m DEM availability and accuracy from a number of satellites necessitates investigation of their advantages over $30 \mathrm{~m}$ public DEMs in representing derivatives of elevation for channel and hillslope analysis in lieu of lidar.

This study presents a multi-DEM validation and comparison for the southern Central Andes in NW Argentina in an arid landscape with no vegetation cover, ideal for remote sensing. DEM validation is presented by (i) reporting the vertical accuracy of a number of satellite-derived DEMs at resolutions of 5-30 m from open-access portals, commercial sources, and research agreements and (ii) carrying out channel profile analysis and geomorphic metric comparisons for a $66 \mathrm{~km}^{2}$ catchment with a defined channel knickpoint to assess the quality of these DEMs for tectonic geomorphology. Through this analysis we demonstrate state of the art wide areal coverage, satellite-derived DEM availability for geomorphometry.

\section{Study area}

The Puna de Atacama Plateau in NW Argentina (Fig. 1a) is the southern extension of the low-relief high-elevation internally drained Central Andean Plateau (also referred to as the Altiplano-Puna Plateau), extending for over $1500 \mathrm{~km}$ and reaching widths of over $350 \mathrm{~km}$ in the Central Andes (Allmendinger et al., 1997). Due to the plateau's hyper-arid climate caused by orographic blocking and regional atmospheric circulation patterns (Bookhagen and Strecker, 2008; Rohrmann et al., 2014), there is an absence of cloud and vegetation cover on the Puna de Atacama Plateau, creating ideal conditions for remote sensing of the bare-earth surface. As the Puna de Atacama Plateau is largely uninhabited and erosion rates are very low (Bookhagen and Strecker, 2012), the study site is a pristine environment experiencing little change from year to year, thus minimizing differences between DEMs collected years apart. Topographic expression is diverse on the plateau, with flat salars (salt flats) having near-zero relief at $5-10 \mathrm{~km}$ scales, surrounded by steep volcanoes and mountain ranges with $>2 \mathrm{~km}$ of relief at $2-$ $5 \mathrm{~km}$ scales. This morphology is readily apparent around the Pocitos Basin, centered on the Salar de Pocitos (basin elevation at $\sim 3600 \mathrm{~m}$ ) and bordered by mountains such as the Nevado Queva, which reach elevations of over $6000 \mathrm{~m}$ (Fig. 1b). Within the Pocitos Basin, we focus geomorphometric analysis on the $66 \mathrm{~km}^{2}$ Quebrada Honda catchment, with $1.2 \mathrm{~km}$ of relief (Fig. 1c). The Quebrada Honda was chosen for its size, coverage across available DEMs, uniform Paleozoic metasedimentary lithology, and the presence of a knickpoint $7 \mathrm{~km}$ upstream of the outlet, dividing the basin into transient and steady-state geomorphic regimes.

\section{Data and methods}

\section{1 dGPS data}

Vertical accuracy of optical and radar DEMs was assessed using a differential GPS (dGPS) dataset spanning $\sim 4000 \mathrm{~m}$ of elevation and covering an area of $\sim 50000 \mathrm{~km}^{2}$ centered on the Pocitos Basin (Fig. 1a). Of 333555 total raw dGPS measurements collected during field campaigns from 2013 to 2016, 307509 kinematically corrected points with vertical and horizontal accuracies $<0.5 \mathrm{~m}$ were selected for the final control on DEM vertical accuracy. Data were projected to the EGM96 geoid vertical and WGS84 horizontal datums in the UTM coordinate system zone 19S. This point measurement dataset was rasterized to the resolution and extent of each DEM. Multiple measurements within a DEM pixel were averaged and pixels without measurements were set to no data. This led to a reduction in the number of individual measurements used to assess DEM vertical accuracy, but it accounted for multiple measurements per pixel to provide a robust validation. Details of measurement collection and kinematic correction of the raw dGPS files using the Universidad Nacional 

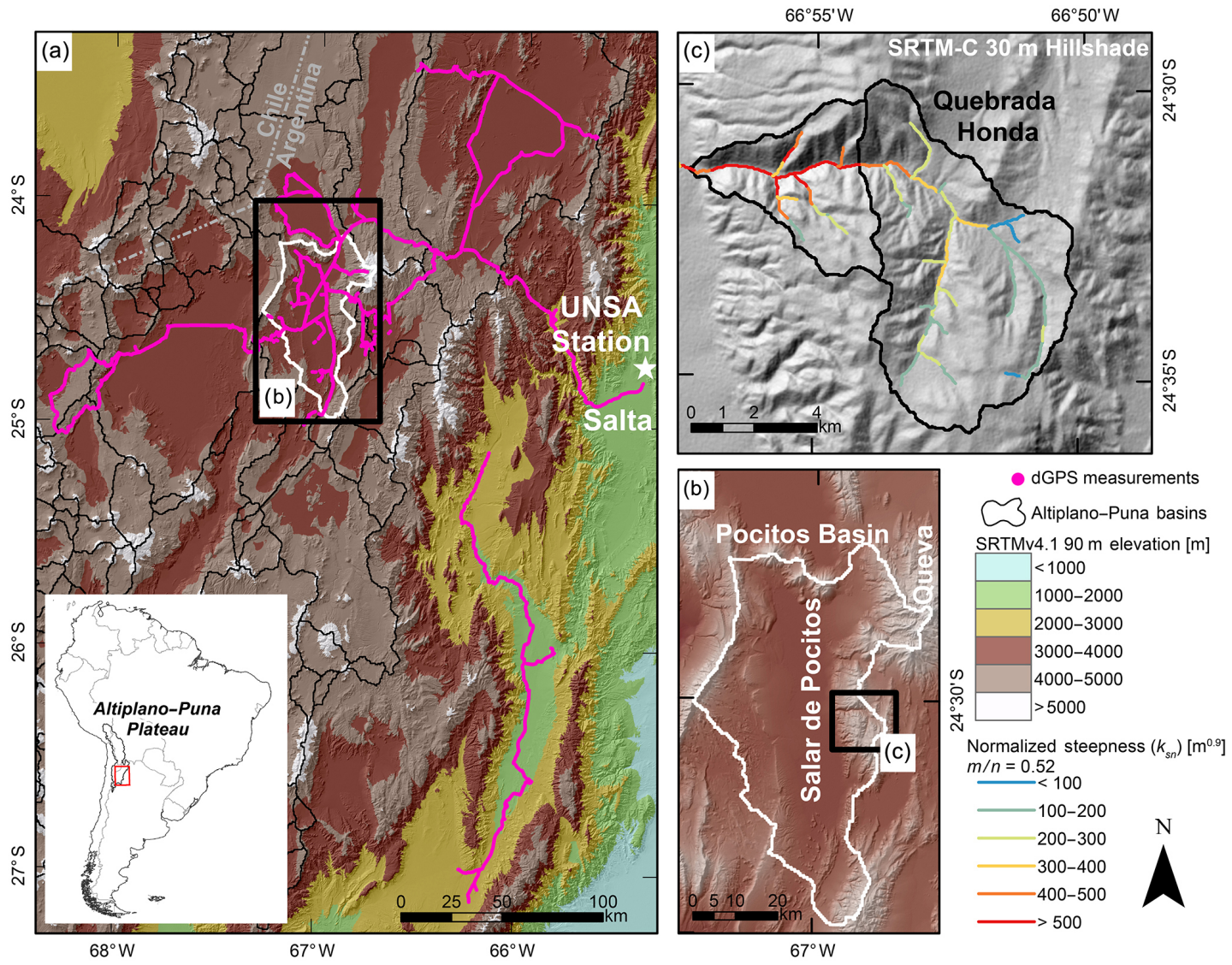

Figure 1. (a) Topographic overview of the study area in the southern Central Andes. Displayed in pink are 307509 dGPS measurements. UNSA base station (white star) for dGPS kinematic correction located in Salta, Argentina. Inset shows South American continent with international borders and internally drained Central Andean Plateau. Study focus is the Pocitos Basin (b), where elevation ranges from $3600 \mathrm{~m}$ on the flat salar to $6000 \mathrm{~m}$ on surrounding peaks. Geomorphometric analyses focus on the Quebrada Honda (c) catchment, draining an area of $66 \mathrm{~km}^{2}$ from $5000 \mathrm{~m}$ of elevation down to $3800 \mathrm{~m}$. A knickpoint $7 \mathrm{~km}$ upstream divides the basin into an upper and lower section with differing morphology (Fig. 2). The transition is observable along the trunk as normalized channel steepness $\left(k_{\mathrm{sn}}\right)$ averaged along $300 \mathrm{~m}$ reaches on the SRTM-C $30 \mathrm{~m}$ DEM increases to values $>500$. The $m / n$ reference value of 0.52 is calculated using chi plot analysis. Elevations in panels (a) and (b) are from the $90 \mathrm{~m}$ SRTMv4.1 DEM (Jarvis et al., 2008).

de Salta (UNSA) permanent station in Salta (Fig. 1a) can be found in the Supplement.

\subsection{DEM datasets}

DEMs collected from a number of public, commercial, and research agreement sources are listed in Table 1. All were referenced to the same datums (EGM96-WGS84) and projected onto UTM 19S using bilinear interpolation. The EGM96 undulation was subtracted from the TanDEM-X and singleCoSSC TDX DEMs to adjust their vertical datum (Baade and Schmullius, 2016). DEMs were co-registered to a common control - the $30 \mathrm{~m}$ SRTM-C, selected for its excellent geolocation accuracy (Rodriguez et al., 2006) - using affine parameters by up- or down-sampling the SRTM-C to the resolution of the DEM of interest and iteratively shifting to reduce the RMSE of the elevation difference using the MAT$\mathrm{LAB}$ function imregister. By aligning datasets to one an- other, we minimize elevation uncertainty versus the dGPS measurements caused by slight offsets in geolocation of the DEMs (e.g., Nuth and Kääb, 2011). Co-registration was not carried out on the TanDEM-X data, as the SRTM-C was already used during initial processing steps to provide elevation corrections (Wessel, 2016). Additional information on each dataset listed in Table 1 is found in the Supplement, including datasets that were not included in the rest of the study due to lower resolution, lack of coverage, or quality issues (SRTMv4.1 90 m, SRTM-X 30 m, RapidEye $12 \mathrm{~m}$, SPOT6 $5 \mathrm{~m}$, ALOS PRISM tri-stereopair $10 \mathrm{~m}$, TerraSAR-X pairs $10 \mathrm{~m}$, and single-CoSSC TerraSAR-X/TanDEM-X processed to $5 \mathrm{~m}$ ).

\section{ASTER stacking}

The ASTER radiometer has collected along-track stereopairs with near-infrared cameras looking toward the nadir 
Table 1. List of DEMs used for comparisons and geomorphic analyses.

\begin{tabular}{|c|c|c|c|c|}
\hline $\begin{array}{l}\text { Dataset } \\
\text { (short name) }\end{array}$ & Data type & $\begin{array}{l}\text { Resolution } \\
(\mathrm{m})\end{array}$ & Source & Notes \\
\hline $\begin{array}{l}\text { SRTM C-band } \\
\text { (SRTM-C) }\end{array}$ & $\begin{array}{l}\text { Radar, edited } \\
\text { global product }\end{array}$ & 30 & $\begin{array}{l}\text { Public, } \\
\text { https://lta.cr.usgs.gov/ } \\
\text { SRTM1Arc }\end{array}$ & $\begin{array}{l}\text { Collected in February 2000, released } \\
2014 \text {, previously only US coverage. }\end{array}$ \\
\hline $\begin{array}{l}\text { ASTER GDEM } \\
\text { Version } 2 \text { (ASTER } \\
\text { GDEM2) }\end{array}$ & $\begin{array}{l}\text { Optical, edited } \\
\text { global product }\end{array}$ & 30 & $\begin{array}{l}\text { Public, } \\
\text { https://asterweb.jpl.nasa.gov/ } \\
\text { gdem.asp }\end{array}$ & $\begin{array}{l}\text { Released 2011, update of ASTER } \\
\text { GDEM1 released 2009. Generated by } \\
\text { automated processing and stacking of } \\
\text { ASTER L1A stereopairs by NASA and } \\
\text { METI }^{\mathrm{a}} \text {. }\end{array}$ \\
\hline $\begin{array}{l}\text { ASTER L1A } \\
\text { stereopair stack } \\
\text { (ASTER stack) }\end{array}$ & $\begin{array}{l}\text { Optical, raw } \\
\text { stereopairs }\end{array}$ & 30 & $\begin{array}{l}\text { Public, } \\
\text { http://reverb.echo.nasa.gov/ } \\
\text { reverb/ }\end{array}$ & $\begin{array}{l}\text { Stacked DEM generated for this study } \\
\text { by stereogrammetric processing of } \\
\text { eight raw L1A stereopairs (Sect. 3.2, } \\
\text { ASTER stacking). }\end{array}$ \\
\hline $\begin{array}{l}\text { ALOS World 3D } \\
\text { (AW3D5 and } \\
\text { AW3D30) }\end{array}$ & $\begin{array}{l}\text { Optical, edited } \\
\text { global product }\end{array}$ & $5 / 30$ & $\begin{array}{l}\text { Public }(30 \mathrm{~m}) \text {, } \\
\text { http://www.eorc.jaxa.jp/ALOS/ } \\
\text { en/aw3d30/ } \\
\text { Commercial }(5 \mathrm{~m}) \text {, } \\
\text { http://aw3d.jp/en/ }\end{array}$ & $\begin{array}{l}5 \mathrm{~m} \text { DEM released } 2015 \text { as highest-res- } \\
\text { olution commercial global DEM, with } \\
\text { down-sampled } 30 \mathrm{~m} \text { research version } \\
\text { released } 2016 .\end{array}$ \\
\hline $\begin{array}{l}\text { Single-CoSSC }^{\mathrm{b}} \\
\text { TerraSAR-X/ } \\
\text { TanDEM-X } \\
\left(_{\text {CoSSC TDX) }}{ }^{\mathrm{a}}\right.\end{array}$ & $\begin{array}{l}\text { Radar, raw } \\
\text { interferograms }\end{array}$ & 10 & $\begin{array}{l}\text { Research agreement, } \\
\text { http://terrasar-x.dlr.de/ }\end{array}$ & $\begin{array}{l}\text { DEMs generated for this study by single } \\
\text { CoSSC TerraSAR-X/TanDEM-X radar } \\
\text { pairs. Same data used by DLR to gen- } \\
\text { erate the stacked TanDEM-X DEM in } \\
2015 \text {. }\end{array}$ \\
\hline $\begin{array}{l}\text { TanDEM-X DEM } \\
\text { (TanDEM-X } 12 \mathrm{~m} \\
\text { and TanDEM-X } \\
30 \mathrm{~m})\end{array}$ & $\begin{array}{l}\text { Radar, edited } \\
\text { global product }\end{array}$ & $12 / 30$ & $\begin{array}{l}\text { Research agreement, } \\
\text { http://tandemx-science.dlr.de/ }\end{array}$ & $\begin{array}{l}\text { Final } 12 \mathrm{~m} \text { DEM generated by stack- } \\
\text { ing of overlapping CoSSC TerraSAR-X/ } \\
\text { TanDEM-X radar pair DEMs and down- } \\
\text { sampled } 30 \mathrm{~m} \text { version, both from DLR }{ }^{\mathrm{c}} \text {. }\end{array}$ \\
\hline
\end{tabular}

a Ministry of Economy, Trade and Industry (METI) of Japan.

b Co-registered Single Look Slant Range Complex (CoSSC) raw interferometric product from DLR.

${ }^{\mathrm{c}}$ Commercial $12 \mathrm{~m}$ product available as WorldDEM ${ }^{\mathrm{TM}}$ from AIRBUS.

(Band $3 \mathrm{~N}$ ) and backwards (Band 3B) between $83^{\circ} \mathrm{S}$ and $83^{\circ} \mathrm{N}$ since 1999 (Tachikawa et al., 2011). Using these stereopairs, a $30 \mathrm{~m}$ ASTER global DEM has been generated by automatic stereo correlation, stacking, and averaging of over 1.2 million scenes. The stacking of multiple lower-quality DEMs from the same source is a common technique, also undertaken to generate the $12 \mathrm{~m}$ TanDEM-X (from singleCoSSC TDX DEMs) and $5 \mathrm{~m}$ ALOS World 3D (from ALOS PRISM optical tri-stereopair DEMs). The 2011 release of the ASTER GDEM version 2 (ASTER GDEM2) used in the present study represented a vast improvement in quality (Tachikawa et al., 2011), but remaining noise is caused by issues with cloud cover, water masking, the smaller stereo correlation kernel, and misregistration of scenes prior to stacking (Nuth and Kääb, 2011). We seek to improve on the ASTER GDEM2 using eight raw ASTER L1A 3N/B stereopairs downloaded with variable overlap from the Pocitos Basin. Using stereogrammetric processing methods we generated eight $30 \mathrm{~m}$ DEMs from these stereopairs. Details of
DEM generation along with RMSE of ground control and tie points are presented in the Supplement (Table S1). Each L1A DEM was co-registered to the SRTM-C, manually masked for outliers (locations where clouds or haze in the imagery caused abrupt $>1000 \mathrm{~m}$ steps in the final DEM), and differenced with the SRTM-C. Pixels were weighted with a bisquare scheme based on their correlation with the SRTM-C, and a weighted average of the overlapping DEMs was used to generate a higher-quality $30 \mathrm{~m}$ ASTER stack.

\subsection{Elevation accuracy assessment}

To assess DEM vertical accuracy, we first performed a pixelby-pixel comparison of rasterized dGPS (vertical uncertainty $<0.5 \mathrm{~m}$ ) and DEM elevation values after co-registration to the SRTM-C. Our preferred metric for DEM vertical accuracy is the mean \pm 1 -sigma $(\sigma)$ standard deviation (SD) (Li, 1988; Fisher and Tate, 2006). Specifically, we are interested in the SD of DEM elevation versus dGPS height as 
our quality metric. Plotted histograms of uncertainty distribution were normalized by their respective mean offsets so the SD could be visually compared. Differences of $\pm 30 \mathrm{~m}$ were filtered out as outliers caused by bad data and processing errors, and the percentage reduction in number of measurements from this filtering is reported along with the prefiltering mean and SD. While many other studies suggest additional statistical tests (e.g., Höhle and Höhle, 2009), our simplified method allows us to move into further analysis of the derivatives of elevation. We have compared the full error distribution, but note that the mean and SD capture the essence. The key is the spatial correlation or consistency of the DEM data because geomorphometric studies use the spatial content of DEMs and higher-order derivatives and not absolute elevation values.

In a second step, we examined error distributions with respect to terrain slope, aspect, and elevation for the DEMs, also normalized by mean offset, with $\pm 30 \mathrm{~m}$ outliers excluded. Measurements were separated into $50-100 \mathrm{~m}$ elevation bins (depending on the full elevation range of the dataset), slopes were calculated from their eight neighboring pixels using the D8 algorithm and binned by $1^{\circ}$, and aspect (also D8 calculated) was binned by $10^{\circ}$, with north at $0^{\circ}$ and east at $90^{\circ}$. Vertical uncertainty was plotted in each bin as a box plot showing the median, 25-75th percentile range, and first and 99th percentile outlier cutoffs.

\subsection{Geomorphometric analysis}

For a robust assessment of DEM quality, we go beyond pixel-by-pixel vertical accuracy comparisons by comparing longitudinal channel profiles and derived geomorphic metrics in the $66 \mathrm{~km}^{2}$ Quebrada Honda catchment (Fig. 2). Here, a defined channel knickpoint separates downstream steep and upstream gentle-sloped terrain, and consistent climate and lithology allows us to test hypotheses of basinwide adjustment to river gradients. We focused on a subset of the highest-quality DEMs with the aim of providing an assessment of the effects of different sensors and resolutions (e.g., SRTM-C $30 \mathrm{~m}$, TanDEM-X $12 \mathrm{~m}$ and $30 \mathrm{~m}$, and AW3D5 $5 \mathrm{~m}$ ) and DEM stacking (e.g., CoSSC TDX $10 \mathrm{~m}$ and TanDEM-X $12 \mathrm{~m}$ ) on geomorphometry.

\subsubsection{Channel profile analysis}

Hydrological and geomorphic modeling is an important application of DEMs (Wilson, 2012), and channel network extraction is a necessary step prior to channel profile analysis. Although a number of recently developed methods for channel extraction via channel-head identification now exist (see Hooshyar et al., 2016, for a review), these methods have all been developed on high-resolution lidar data, with control datasets of field-mapped channel heads (Clubb et al., 2014) or channel networks (Passalacqua et al., 2010a, b). We are thus wary to apply these methods to our coarser satellite-derived data with no control from the field and no lidar data for a relative performance assessment. Instead, we use the simplistic threshold area approach (e.g., Tarboton et al., 1991), choosing the common reference area of $1 \mathrm{~km}^{2}$ where breaks in area-slope scaling indicate the changeover to dominantly alluvial channel processes (Montgomery and Foufoula-Georgiou, 1993). Misrepresentation of channel location from this method is entirely restricted to the highest catchment reaches where the channel head lies and does not affect the majority of the downstream channel. The consistent use of area thresholding at the same reference area across DEMs allows the direct comparison of channel profile results in our study.

Advances in longitudinal channel profile analysis driven by accurate DEMs have elucidated changes in boundary conditions recorded in channel slope and upstream-propagating knickpoints (e.g., Wobus et al., 2006; Kirby and Whipple, 2012). The stream power incision model (SPIM) of landscape evolution provides the theoretical basis for relating channel slope and drainage area (see Kirby and Whipple, 2012, or Lague, 2014, for background and limitations of SPIM). Applied to a channel profile in steady state $(\mathrm{d} z / \mathrm{d} t=$ 0 ), we find the relationship

$S_{\mathrm{C}}=\left(\frac{U}{K}\right)^{\frac{1}{n}} A^{\frac{-m}{n}}$,

where $U$ is uplift, $K$ is erodibility, $A$ is local drainage area, $S_{\mathrm{C}}$ is local channel slope, and $m$ and $n$ are site-specific constants that scale the relative influences of climate and tectonics. Important to constrain here is the $m / n$ ratio, used to normalize channel steepness across differently sized drainage areas for the mapping of regional patterns of deformation, climatic influence, and/or lithologic boundary conditions (e.g., Wobus et al., 2006; Kirby and Whipple, 2012; Forte et al., 2016). While Eq. (1) is derived for steady state, its integration (or the use of area-slope plots) to determine the $m / n$ ratio and assess relative differences in channel steepness is a geometric consideration of local channel behavior and can thus be applied in nonequilibrium settings, like the Quebrada Honda. Here, we utilize the recently developed integration method of chi plot analysis (Perron and Royden, 2013) to estimate $m / n$ from our DEMs (see Supplement for details).

Following channel extraction, we first applied the leastsquares $R^{2}$ maximization chi plot technique of Perron and Royden (2013) to the Quebrada Honda trunk stream (Schwanghart and Scherler, 2014). This method attempts to linearize the entire channel to one best-fit line in chi space and does not provide robust uncertainty estimates for $m / n$, as linear regression is performed through serially correlated values of chi distance and elevation (Perron and Royden, 2013). Because of this, we also employed the piece-wise fitting $m / n$ selection algorithm developed by Mudd et al. (2014) on the $30 \mathrm{~m}$ SRTM-C, $10 \mathrm{~m}$ CoSSC TDX, and $5 \mathrm{~m}$ AW3D5 DEMs (representing a cross section of DEM resolutions and sen- 

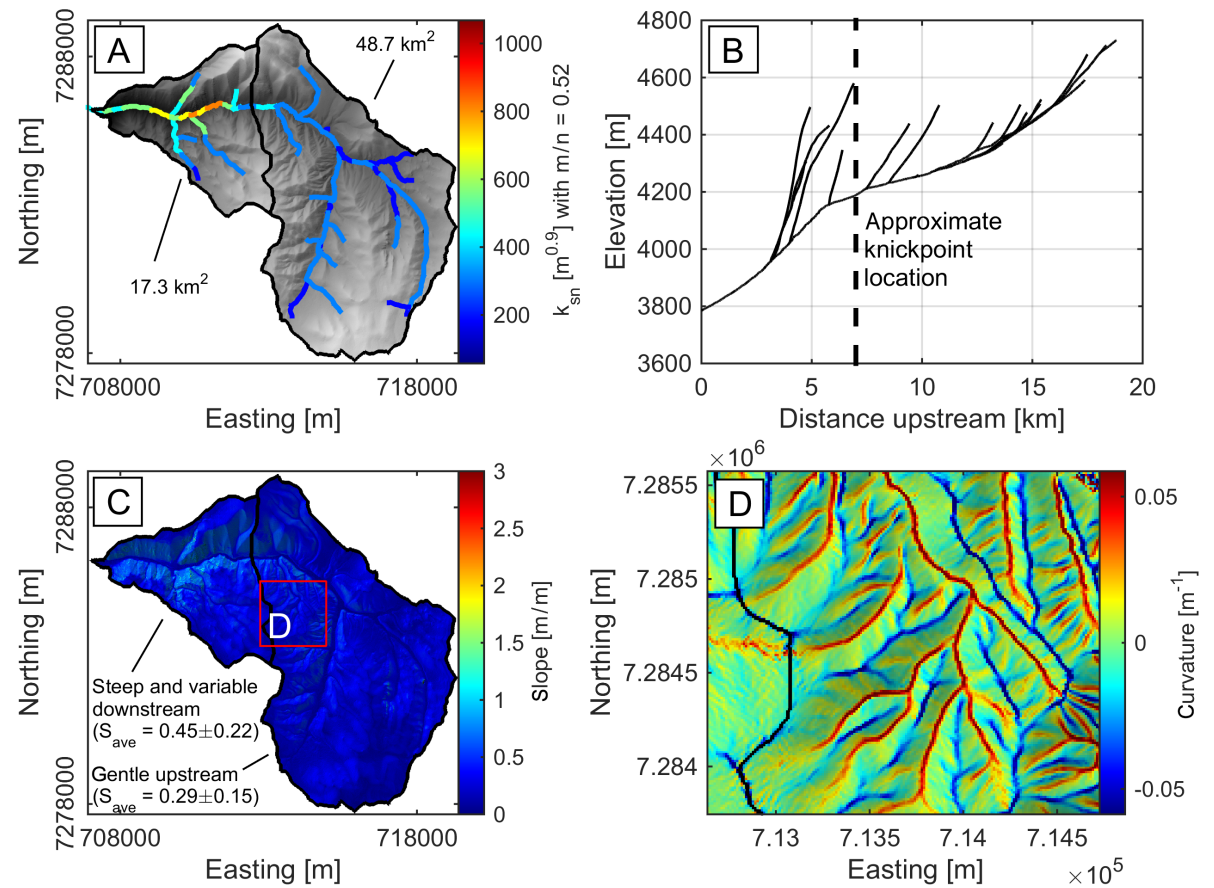

Figure 2. Topographic overview of Quebrada Honda from the $12 \mathrm{~m}$ TanDEM-X DEM. (a) Normalized channel steepness $\left(k_{\mathrm{sn}}\right)$ averaged over $300 \mathrm{~m}$ reaches using $m / n=0.52$ with upstream and downstream drainage areas indicated by black outlines. All tributaries with a drainage area $>1 \mathrm{~km}^{2}$ are plotted. Note oversteepened trunk signal has not propagated entirely up all downstream tributaries, as indicated by $k_{\mathrm{sn}}<400$ in upper reaches. (b) Longitudinal profile of trunk channel and tributaries with knickpoint indicated. (c) D $\infty$ slope map (Tarboton, 2005) displaying steeper, more variable topography downstream of knickpoint, indicated by warmer colors and greater average slope $\left(S_{\text {ave }}\right)$ and standard deviation. (d) Curvature colored by $\pm 3 \sigma$ range with positive values concave (valleys) and negative values convex (hilltops). Note the planar slopes separating ridges and valleys and the increase in concavity near valley heads, indicating the shift from hillslope to fluvial processes.

sors) for comparison with the least-squares approach. This method balances goodness of fit for the piece-wise fit profile with model complexity (number of parameters and segments) to provide an $m / n$ at the minimum corrected Akaike information criterion (AICc) (Akaike, 1974; Hurvich and Tsai, 1989). A SD (uncertainty) of this minimum AICc is also provided, over which AICc values falling within the SD range indicate other plausible $m / n$ values (Mudd et al., 2014). Sensitivity tests were performed by varying fitting parameters, with final parameters reported in the Supplement.

\subsubsection{Hillslope geomorphic metrics}

In addition to channel profile analysis, signals of denudation and uplift may also be inferred from hillslope morphology as determined by geomorphic metrics, including characteristic hillslope length, local relief, slope angles, and curvature. These parameters allow the exploration of empirical geomorphic transport laws, which aid in topographic modeling over geologic timescales (see Dietrich et al., 2003). In particular, the accurate sampling of slope angles and curvatures allows patterns of erosion to be mapped from topography alone, thus playing key roles in geomorphic studies focused on the topographic expression of tectonic-climatic forcing (e.g., DiBiase et al., 2010; Hurst et al., 2012). Here, we test the newest generation of satellite-derived DEMs for assessing slope and curvature as well as the hillslope-tovalley transition marked by inflections in plots of slope, curvature, and drainage area to examine differences related not only to the channel knickpoint, but also to the resolution and quality of the DEM. We compared results between the highquality $30 \mathrm{~m}$ SRTM-C, $30 \mathrm{~m}$ and $12 \mathrm{~m}$ TanDEM-X, $10 \mathrm{~m}$ CoSSC TDX, and $5 \mathrm{~m}$ AW3D5 DEMs. We did not include the ASTER DEMs in hillslope analyses because of elevation noise prevalent in these $30 \mathrm{~m}$ DEMs apparent in vertical uncertainty reporting $(>6 \mathrm{~m})$ and visual inspection. Despite low vertical uncertainty $(<3 \mathrm{~m})$, we also excluded the newly released $30 \mathrm{~m}$ AW3D30 because of unknown preprocessing steps taken to produce this DEM, which may have compounded high-frequency noise present in the $5 \mathrm{~m}$ AW3D5.

Since hillslopes represent a diffusive environment where flow is multidirectional, we calculated drainage area and slope at every pixel in the Quebrada Honda using the $\mathrm{D} \infty$ algorithm, allowing dispersive flow (Tarboton, 2005). Curvature was calculated using the Laplacian of elevation (e.g., 
Tarolli and Dalla Fontana, 2009):

$C=\nabla^{2} z=\left(\frac{\delta^{2} z}{\delta x^{2}}+\frac{\delta^{2} z}{\delta y^{2}}\right)$,

where concavity (valleys and channels) is denoted by $C>0$, convexity (hillslopes and ridges) is denoted by $C<0$, and planar slopes are denoted by $C=0$ (Fig. 2d). Distributions of slope and curvature separated upstream and downstream of the knickpoint were visualized as box plots displaying medians, 25-75th percentile ranges, first and 99th percentile cutoffs, and all outlier measurements.

Filtering is a common step to smooth DEM noise before deriving geomorphic metrics, as the calculation of slope via steepest-descent algorithms is greatly affected by elevation errors in neighboring pixels (e.g., Raaflaub and Collins, 2006). However, here we use the $\mathrm{D} \infty$, which is less susceptible to these effects, as slope is divided between two cells. Often filtering is also done to reduce noise associated with shorter timescale geomorphic features, like tree throw, from high-resolution lidar DEMs (Grieve et al., 2016a). During initial tests we experimented with median, diffusion (Passalacqua et al., 2010b), and Wiener filtering (Wiener, 1949) prior to slope and curvature calculations. However, since all smoothing techniques were found to reduce the variability in slope and curvature measurements and blur sharper features of interest such as ridge crests and valley bottoms, we instead chose to measure derivatives from the raw elevation data.

To explore the influence of the oversteepened trunk reach on hillslope morphology, we combined measures of cur-

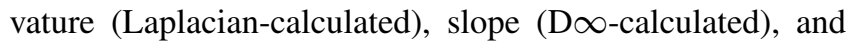
drainage area (also $\mathrm{D} \infty$-calculated) at every DEM pixel in the Quebrada Honda to explore differences between the gentle upstream and steep downstream catchment. We are particularly interested in differences at the hillslope-tovalley transition demarcated by the first inflection in plots of slope binned by area, occurring at a critical drainage area where channel heads are thought to initiate (Montgomery and Foufoula-Georgiou, 1993; Zhang and Montgomery, 1994; Ijjasz-Vasquez and Bras, 1995; Tarolli and Dalla Fontana, 2009). We generated plots of logarithmically binned contributing area versus median slope (areaslope), logarithmically binned area versus median curvature (area-curvature), and linearly binned curvature versus median slope (curvature-slope) - all separated upstream and downstream of the knickpoint. For area-slope plots the gradient at the graphical rollover in binned area is recorded along with this area bin. We also attempted rollover identification using 2-D kernel density estimates (Botev et al., 2010) to identify the densest concentrations of slope and area values demarcating the approximate rollover, but we found similar results to the graphical approach. Following the method of Roering et al. (2007), we divide the rollover drainage area by DEM resolution to approximate the characteristic horizontal hillslope length $\left(L_{\mathrm{H}}\right)$, providing an additional check on DEM applicability to geomorphology. This method relies on the assumption that DEM resolution is equivalent to unit contour width, which may be an oversimplification. Despite this caveat, the resolution, or unit contour width, serves as a constant for division, and differences between values will not alter the trend of the results. We use the horizontal definition of $L_{\mathrm{H}}$ since the difference between horizontal and downslope $L_{\mathrm{H}}$ (as measured by Grieve et al., 2016a, b, c) should be minimal, except for very high slope angles. Area-curvature and curvature-slope plots are used to visualize the slope and area trends related to curvature, particularly around the zero curvature planar inflection point in the landscape (Roering et al., 1999).

\subsection{Two-dimensional fourier analysis}

In a final step, we employ a two-dimensional discrete Fourier transform (2-D DFT) to quantify high-frequency noise in select datasets using $8 \mathrm{~km}$ by $14 \mathrm{~km}$ DEM clips centered on the Quebrada Honda. This common signal processing tool (Priestley, 1981) relies on the transformation of elevation matrices from the spatial to the frequency domain, providing information about the amplitude and periodicity of landscape features. Prior work using the 2-D DFT on gridded topography has focused on artifact identification (Arrell et al., 2008), landscape organization and scaling (e.g., Perron et al., 2008 and references therein), the identification of landslides (Booth et al., 2009), and the length scales of biotic influence on topography (Roering et al., 2010). We follow the methods outlined in Perron et al. (2008) and take the 2-D DFT of a rectangular elevation matrix, $z(x, y)$, with $N_{x} \times N_{y}$ measurements spaced evenly by $\Delta x$ and $\Delta y$ (Priestly, 1981; Perron et al., 2008; Booth et al., 2009):

$$
Z\left(k_{x}, k_{y}\right)=\sum_{m=0}^{N_{x}-1} \sum_{n=0}^{N_{y}-1} z(m \Delta x, n \Delta y) e^{-2 \pi i\left(\frac{k_{x} m}{N_{x}}+\frac{k_{y} n}{N_{y}}\right)},
$$

where $k_{x}$ and $k_{y}$ are wave numbers and $m$ and $n$ are indices of $z$. This transformation outputs an array with the amplitudes of the frequency components, from which the power spectrum can be calculated using the DFT periodogram:

$P_{\mathrm{DFT}}\left(k_{x}, k_{y}\right)=\frac{1}{N_{x}^{2} N_{y}^{2}}\left|Z\left(k_{x}, k_{y}\right)\right|^{2}$.

The $P_{\mathrm{DFT}}$ array is a measure of the variance of $z$ and has units of amplitude squared (square meters). To enhance visualization, this array is plotted against radial frequency in one dimension as wavelength (frequency ${ }^{-1}$ ) versus meansquared amplitude. Here, the wavelength represents the spatial scale (in meters) of the amplitude fluctuations, and can thus be converted to pixel steps given the DEM resolution. A linear regression through logarithmically spaced wavelength bins (at the mean value) is used as the background spectrum to normalize the mean-squared amplitude, as opposed to the randomly generated surfaces in Perron et al. (2008). Use of 
the median of the wavelength bins in the linear regression provided comparable results to the mean, with the $R^{2}$ value in all cases $>0.98$. Although this regression is somewhat skewed by the longest wavelength (lowest-frequency) values (Fig. S10), we are interested only in the high-frequency noise, which is effectively normalized here.

Through these steps, we achieve a 1-D plot of wavelength versus unitless spectral power that highlights largeamplitude outliers at specific low wavelengths for the $30 \mathrm{~m}$ SRTM-C, $12 \mathrm{~m}$ TanDEM-X, and $5 \mathrm{~m}$ AW3D5 DEMs. To test whether the DEM noise had an orientation-dependent spatial structure requiring a 2-D plotting scheme, we carried out the same analysis on each elevation matrix rotated $90^{\circ}$ and found comparable results in the 1-D plots. Further details of this methodology, including topographic detrending and windowing functions to reduce spectral leakage, can be found in Perron et al. (2008). To quantitatively compare the 1-D graphical results of the 2-D DFT analysis between the $12 \mathrm{~m}$ TanDEM-X and $5 \mathrm{~m}$ AW3D5, we rely on the twosample Kolmogorov-Smirnov (KS) test (Massey, 1951) and quantile-quantile (QQ) plots. These statistical techniques allow the direct comparison of normalized spectral power distributions from samples with different sizes (different resolutions) without the need for resampling of the data to a common resolution (e.g., $10 \mathrm{~m}$ ), which introduces biases in the spectral analysis depending on the resampling scheme (e.g., bilinear, cubic, spline).

\section{Results}

\subsection{Elevation accuracy}

Vertical uncertainties, measured as the mean \pm SD of differences between DEM elevation and rasterized dGPS height, for all DEMs are summarized in Table 2.

Histograms of the vertical uncertainty distributions are plotted for the $30 \mathrm{~m}$ (Fig. 3) and higher-resolution DEMs (Fig. 4). The $30 \mathrm{~m}$ SRTM-C and TanDEM-X both demonstrated a very low SD and smooth appearance upon visual inspections, with the TanDEM-X having the lowest SD $(2.42 \mathrm{~m})$ and narrowest distribution (Fig. 3a) of all $30 \mathrm{~m}$ DEMs. Conversely, despite a low SD, visual inspection of numerous artifacts in the AW3D30 with no landscape representation demonstrated its lower quality. The improvement in quality through weighted stacking of ASTER L1A stereopair DEMs versus the low-quality ASTER GDEM2 is apparent in the reduction of the SD from $11.42 \mathrm{~m}$ for a single L1A DEM to $6.93 \mathrm{~m}$ for the stack, although uncertainty distributions for all ASTER DEMs extend beyond the $\pm 30 \mathrm{~m}$ outlier cutoff (Fig. 3b).

For the higher-resolution DEMs, we note the narrow uncertainty distributions with very few $\pm 30 \mathrm{~m}$ outliers (Fig. 4). The $5 \mathrm{~m}$ AW3D5 has the lowest vertical SD of any DEM at $1.64 \mathrm{~m}$. Importantly, the $12 \mathrm{~m}$ TanDEM-X DEM has a similarly low SD of $1.97 \mathrm{~m}$ but covers a much larger area of dGPS measurements $\left(\sim 50000 \mathrm{~km}^{2}\right.$ for the TanDEM-X versus $\sim 580 \mathrm{~km}^{2}$ for the AW3D5), as indicated by the order of magnitude difference in counts. The wider, doublepeaked vertical uncertainty distributions for the 6 November 2012 and 25 August 2013 CoSSC TDX DEMs are caused by their coverage over variable terrain east of the Salar de Pocitos, where accurate DEM generation is complicated by radar shadowing and layover in steeper topography. Visual inspection of these two DEMs containing the full Quebrada Honda catchment revealed minor hillslope artifacts often coinciding with rocky outcrops and other steep and rough features, occurring in only a few areas representing a small $\left(<0.5 \mathrm{~km}^{2}\right)$ portion of the catchment relative to the total area from which geomorphic metrics were derived $\left(66 \mathrm{~km}^{2}\right)$. Since the 2013 CoSSC TDX DEM had noticeable striping from radar processing, the $10 \mathrm{~m}$ CoSSC TDX DEM from 6 November 2012 was selected for further geomorphic comparison.

In addition to histograms, the vertical uncertainty distributions with respect to elevation, slope, and aspect of the topography are plotted for our highest-quality datasets (Figs. 57), with additional plots in the Supplement (Figs. S4S9). On each plot the dearth of dGPS measurements on slopes $>30^{\circ}$ is noted, as the majority of measurements were taken from low-gradient roads and flat salars. For our $30 \mathrm{~m}$ datasets, a narrow uncertainty range across all terrain attributes is apparent for the SRTM-C (Fig. 5), TanDEM-X (Fig. S7), and AW3D30 (Fig. S4). Conversely, the ASTER GDEM2 (Fig. S5) had the largest error distribution across all attributes, with even low-slope $\left(0-3^{\circ}\right)$ errors extending above $\pm 10 \mathrm{~m}$. Prevalent noise in the ASTER GDEM2 is also demonstrated by the greater number of measurements (> 15 000) taken from a greater-than-realistic landscape representation with only 6000-7000 measurements recorded on $>10^{\circ}$ slopes. Furthermore, the ASTER GDEM2 appears to have a slight aspect-related bias, with an amplitude of $\sim 5 \mathrm{~m}$ repeating at approximately ENE, SE, WSW, and NNW (Fig. S5c), which is not evident in any other $30 \mathrm{~m}$ DEMs. We note that this aspect bias is removed in the ASTER stack (Fig. S6); however, this stacked $30 \mathrm{~m}$ DEM still has large error bars and covers only the Pocitos Basin and thus far fewer measurements than the full ASTER GDEM2. For the SRTM-C, $30 \mathrm{~m}$ TanDEM-X, and AW3D30, error bars grow with slope and the smallest errors are consistently found in flat topography with slopes $<10^{\circ}$. At low slopes $\left(0-3^{\circ}\right)$, the $30 \mathrm{~m}$ TanDEM-X performs exceedingly well, with first and 99th percentile outlier cutoffs within $\pm 5 \mathrm{~m}$ (Fig. S7b). The TanDEM-X performance is further enhanced in the $12 \mathrm{~m}$ version (Fig. 6), which has error bars mostly within $\pm 5 \mathrm{~m}$ across the range of terrain attributes (with the exception of some limited high-slope measurements). Furthermore, the $12 \mathrm{~m}$ TanDEM-X does not have the aspect bias noted in the $10 \mathrm{~m}$ CoSSC TDX DEMs (Figs. S8-S9), which have a 5-10 m bias repeating at approximately due $\mathrm{N}, \mathrm{E}, \mathrm{S}$, and $\mathrm{W}$, likely related to satellite slant angles. Unsurprisingly, from Table 2 and histogram plotting results, the $5 \mathrm{~m}$ AW3D5 has the small- 
Table 2. Results of pixel-by-pixel DEM vertical accuracy (DEM minus dGPS). Mean and standard deviation before filtering denoted in parentheses, with a value of $\mathrm{n} / \mathrm{a}$ if there were no outliers filtered.

\begin{tabular}{lrrrr}
\hline Dataset & Mean $(\mathrm{m})$ & $\begin{array}{r}\text { Standard } \\
\text { deviation } \\
(\mathrm{m})\end{array}$ & $\begin{array}{r}\text { Number of post- } \\
\text { filtered rasterized } \\
\text { measurements }^{\mathrm{a}}\end{array}$ & $\begin{array}{r}\text { Reduction } \\
\text { after } \pm 30 \mathrm{~m} \\
\text { filtering }(\%)\end{array}$ \\
\hline 30 m SRTM-C & $2.18(2.33)$ & $3.33(13.74)$ & 64782 & 0.02 \\
30 m AW3D30 & $1.59(1.66)$ & $2.81(16.19)$ & 63413 & 0.03 \\
30 m ASTER GDEM2 & $-0.15(0.02)$ & $9.48(17.65)$ & 63308 & 2.30 \\
30 m ASTER Stack & $4.56(4.58)$ & $6.93^{\mathrm{c}}(7.00)$ & 15506 & 0.12 \\
30 m TanDEM-X & $-1.29(-1.12)$ & $2.42(14.57)$ & 55791 & 0.02 \\
12 m TanDEM-X & $-1.41(-1.31)$ & $1.97(11.16)$ & 108029 & 0.02 \\
10 m CoSSC TDX (7 February 2011) & $1.99(2.36)$ & $2.02(21.26)$ & 28982 & 0.03 \\
10 m CoSSC TDX (6 November 2012) ${ }^{\mathrm{d}}$ & $1.32(\mathrm{n} / \mathrm{a})$ & $3.83(\mathrm{n} / \mathrm{a})$ & 22182 & 0.00 \\
10 m CoSSC TDX (25 August 2013) & $2.94(\mathrm{n} / \mathrm{a})$ & $3.22(\mathrm{n} / \mathrm{a})$ & 22175 & 0.00 \\
5 m AW3D5 & $2.40(\mathrm{n} / \mathrm{a})$ & $1.64(\mathrm{n} / \mathrm{a})$ & 14306 & 0.00 \\
\hline
\end{tabular}

a After $\pm 30 \mathrm{~m}$ outlier filtering.

${ }^{\mathrm{b}}$ Generated for Pocitos Basin by weighted stacking of eight manually generated ASTER L1A DEMs.

c Compare with 11.42 and $10.06 \mathrm{~m}$ SD for single L1A DEM and ASTER GDEM2, respectively, clipped to same area.

${ }^{\mathrm{d}}$ CoSSC TDX DEM selected for geomorphometric analysis.
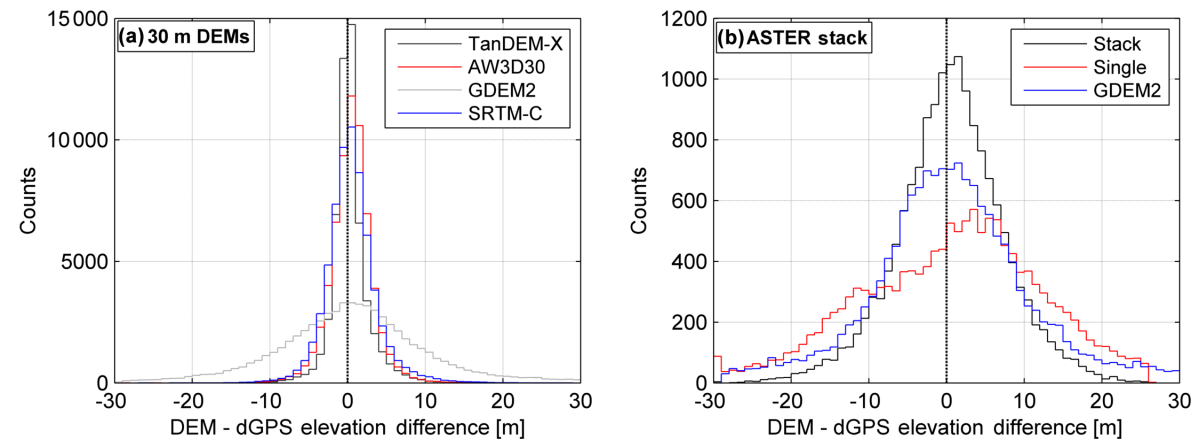

Figure 3. Vertical uncertainties for (a) global $30 \mathrm{~m}$ DEMs and (b) ASTER $30 \mathrm{~m}$ DEMs. Plots have been normalized by mean offsets, with statistics reported in Table 2. Note the order of magnitude difference in counts, as panel (b) covers only the Pocitos Basin $\left(\sim 2500 \mathrm{~km}^{2}\right)$, whereas panel (a) spans all dGPS measurements $\left(\sim 50000 \mathrm{~km}^{2}\right)$ stretching over a $4000 \mathrm{~m}$ elevation range.

est vertical uncertainty error bars of any DEM tested, falling almost entirely within $\pm 5 \mathrm{~m}$ for all bins over all terrain attributes (Fig. 7). We emphasize that this stacked DEM was purchased for only a small area $\left(580 \mathrm{~km}^{2}\right)$, but covers highly variable topography around the Nevado Queva and Quebrada Honda (Fig. 1b).

\subsection{Geomorphometric analysis}

Based on the results of elevation validation and visual inspection of the datasets, we selected the $30 \mathrm{~m}$ SRTM-C, $30 \mathrm{~m}$ and $12 \mathrm{~m}$ TanDEM-X, $10 \mathrm{~m}$ CoSSC TDX from 6 November 2012, and $5 \mathrm{~m}$ AW3D5 for geomorphometric analysis of the Quebrada Honda (Fig. 2). These edited (SRTM-C, TanDEM$\mathrm{X}$, and AW3D5) and single-pair radar (CoSSC TDX) DEMs, all released in the past 3 years, have the highest potential for future studies seeking to derive geomorphic metrics in large regions without lidar.

\subsubsection{Channel profile analysis}

The results of $m / n$ estimation from least-squares $R^{2}$ maximization (Perron and Royden, 2013; Schwanghart and Scherler, 2014) and from piece-wise fitting (Mudd et al., 2014) on the Quebrada Honda trunk channel on three DEMs are summarized in Table 3. Example plots for both methods of the SRTM-C are found in the Supplement (Figs. S2-S3). Not included here are the $30 \mathrm{~m}$ and $12 \mathrm{~m}$ TanDEM-X, as $m / n$ results were similar to those listed. For all DEMs tested and listed in Table 1, the resulting $m / n$ from least-squares fitting was $0.49-0.53$ (all with $R^{2}>0.95$ ), representing the same range as those DEMs listed in Table 3, regardless of DEM vertical accuracy or resolution. For those DEMs tested with the piece-wise fitting method, the $m / n$ range was similar, although slightly higher at $0.53-0.57$. While the least-squares technique takes only a few minutes to setup and run, the computationally intensive piece-wise fitting takes hours to days, although it provides a range of minimum AICc that denote 
Table 3. $m / n$ values using two chi plot methods on the Quebrada Honda trunk.

\begin{tabular}{lrrr|rrrr}
\hline & & \multicolumn{2}{c}{ Least squares $^{\mathrm{a}}$} & \multicolumn{3}{c}{ Piece-wise fitting $^{\mathrm{b}}$} \\
\cline { 2 - 7 } Dataset & $\begin{array}{r}\text { SD of dGPS } \\
\text { uncertainty (m) }\end{array}$ & $m / n$ & $R^{2}$ & $\begin{array}{r}\text { AICc minimum } \\
\text { value } \pm \text { SD }\end{array}$ & $\begin{array}{r}m / n \text { at AICc } \\
\text { minimum }\end{array}$ & $\begin{array}{r}\text { Plausible values } \\
\text { of } m / n^{\mathrm{c}}\end{array}$ \\
\hline $30 \mathrm{~m}$ SRTM-C & 3.33 & 0.53 & 0.97 & $27.98 \pm 0.50$ & 0.55 & $0.55-0.57$ \\
$10 \mathrm{~m}$ CoSSC TDX & 3.83 & 0.49 & 0.97 & $28.89 \pm 0.22$ & 0.54 & $-\mathrm{d}$ \\
5 m AW3D5 & 1.64 & 0.51 & 0.98 & $31.54 \pm 0.21$ & 0.54 & $0.53-0.56$ \\
\hline
\end{tabular}

a Peron and Royden (2013) and Schwanghart and Scherler (2014).

b Mudd et al. (2014).

${ }^{c}$ With corresponding AICc value falling within SD range of AICc minimum.

${ }^{\mathrm{d}}$ No tested values of $m / n$ fell within the AICc SD range.
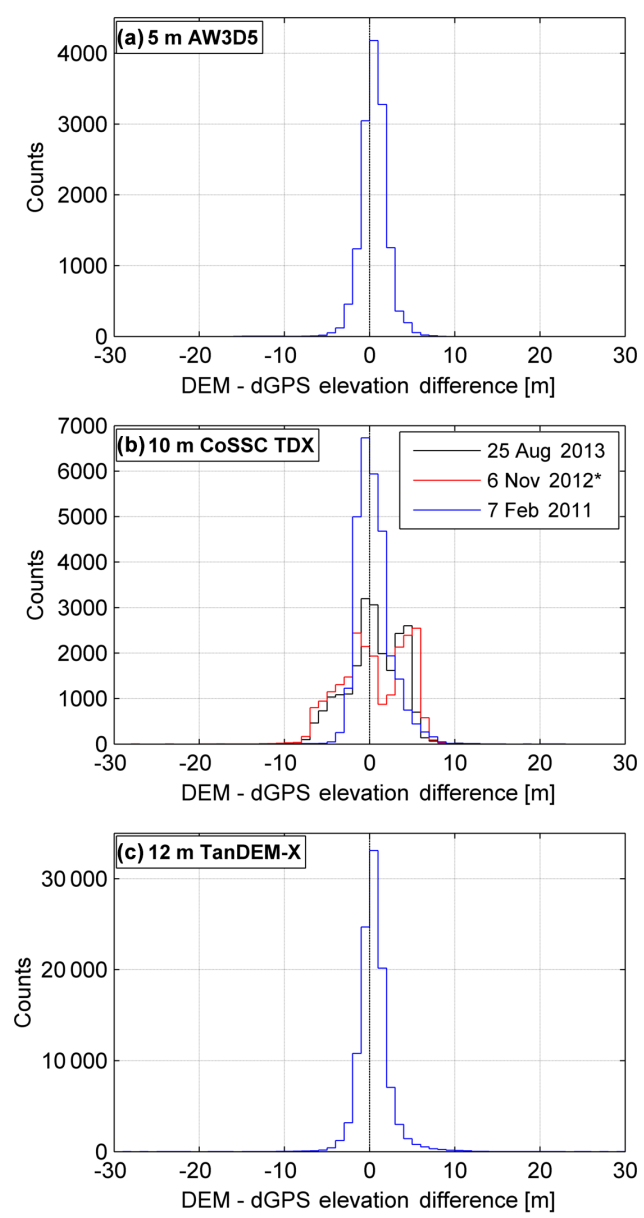

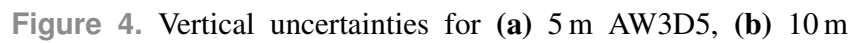
CoSSC TDX, and (c) $12 \mathrm{~m}$ TanDEM-X. Plots have been normalized by mean offsets, with statistics reported in Table 2. The star (*) in panel (b) denotes the 2012 CoSSC TDX DEM selected for geomorphometric analysis. Note the order of magnitude increase in counts for the $12 \mathrm{~m}$ TanDEM-X (c), which covers nearly all dGPS measurements $\left(\sim 50000 \mathrm{~km}^{2}\right)$ stretching over a $4000 \mathrm{~m}$ elevation range. plausible $m / n$ values. Interestingly, the 5 and $10 \mathrm{~m}$ DEMs had slightly lower SD for AICc, perhaps indicating the better fitting of the channel segments compared to the $30 \mathrm{~m}$ DEM.

\subsubsection{Hillslope analysis}

We turn to slope $(\mathrm{D} \infty)$, drainage area $(\mathrm{D} \infty)$, and curvature (Laplacian) geomorphic metrics calculated for every DEM pixel upstream and downstream of the knickpoint to further assess DEM quality at a finer scale than channel analysis. Box plots showing distributions for slope and curvature are presented in Fig. 8. We note that the quartile (boxes) and outlier (whiskers) ranges of slopes are similar regardless of DEM resolution (Fig. 8a). Only the outliers grow in number and spread with finer resolution, demonstrating in particular the greater slope variability measured by the highestresolution AW3D5 DEM. In exception to this trend, more high-slope outliers are measured by the $12 \mathrm{~m}$ TanDEM-X compared with the $10 \mathrm{~m}$ CoSSC TDX. These higher slopes are caused by the better resolution of rocky outcrops and other steep features with very high slopes from the stacked TanDEM-X DEM versus the single-CoSSC TDX DEMs. For curvature distributions (Fig. 8b), the $30 \mathrm{~m}$ SRTM-C and TanDEM-X, $12 \mathrm{~m}$ TanDEM-X, and $10 \mathrm{~m}$ CoSSC TDX have very narrow quartile and outlier ranges compared with the wide distribution of the $5 \mathrm{~m}$ AW3D5. Similar to the slope results, the higher-resolution DEMs measure far more curvature outliers compared to the $30 \mathrm{~m}$ SRTM-C and TanDEM$\mathrm{X}$, whose full distributions extend only to approximately $\pm 0.05 \mathrm{~m}^{-1}$. Regarding differences in distributions related to the catchment knickpoint, median slopes downstream are consistently $0.1-0.2 \mathrm{~m} \mathrm{~m}^{-1}$ greater in magnitude than upstream (Fig. 8a). Conversely, the downstream curvatures have a slightly narrower range compared to the upstream curvatures, especially noticeable in the smaller downstream quartile range from the AW3D5 (Fig. 8b). This is likely caused by the fact that the upstream area $\left(48.7 \mathrm{~km}^{2}\right)$ covers more than twice as much area as downstream $\left(17.3 \mathrm{~km}^{2}\right)$, thus measuring more pixels and leading to a greater range in curvature measured when averaged over the entire subcatchment area. 

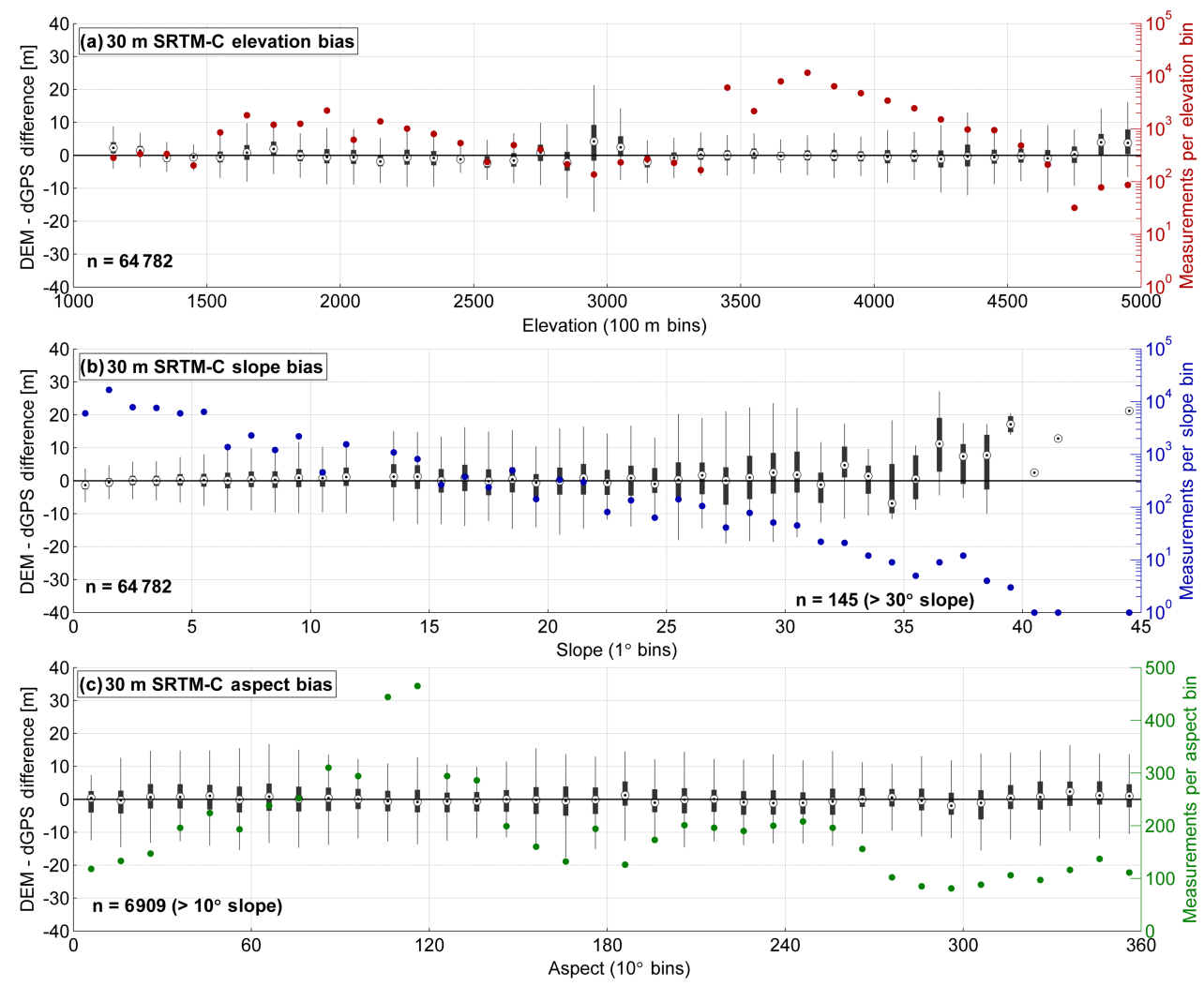

Figure 5. (a) Elevation, (b) slope (eight-connected neighborhood calculated), and (c) aspect (eight-connected neighborhood calculated) vertical uncertainties from $30 \mathrm{~m}$ SRTM-C. Median elevation difference (black circles) with 25-75th percentile range (boxes) and first and 99th percentile outlier cutoff (whiskers) plotted for each bin on left axis. Number of measurements indicated $(n)$ with measurements per bin plotted as colored circles on right axis. For aspect (c), only measurements on slopes $>10^{\circ}$ are used; thus, $n$ is reduced by an order of magnitude. Elevation differences are normalized by mean offset. We note the dearth of slope measurements $>30^{\circ}$ (b).

Higher downstream slopes are reflected in area-slope plots, with median slopes typically $0.1-0.2 \mathrm{~m} \mathrm{~m}^{-1}$ greater in magnitude downstream given the same contributing area (Fig. 9), regardless of DEM resolution. Moving from 30 to $5 \mathrm{~m}$, the values for median local slope (and mean slope at the rollover) change only slightly, again indicating the similar slope values measured across DEMs. Differences in slope given the same drainage area are most pronounced in the $10^{4}-10^{5} \mathrm{~m}^{2}$ drainage area range, with results converging somewhat as drainage area trends towards very high values, until diverging once more in the 5-12 m DEMs at drainage areas $>10^{6} \mathrm{~m}^{2}$ (Fig. 9c-e). All DEMs demonstrate a broad changeover region from hillslope to fluvial processes, indicated by a wide first inflection (Fig. 9). Therefore, the graphical selection of the drainage area rollover is very approximate, and upstream and downstream rollover values do not show significant variation. Conversely, we note that this rollover drainage value does decrease with finer resolution of the DEM, indicating a resolution-dependent bias for this area-slope analysis, likely related to the ability of each DEM to represent the most upstream reaches of a catchment $\left(<10^{4} \mathrm{~m}^{2}\right)$, which may only cover $4-5$ pixels in the
$30 \mathrm{~m}$ DEMs $\left(900 \mathrm{~m}^{2}\right.$ per pixel) versus hundreds in the $5 \mathrm{~m}$ DEMs $\left(25 \mathrm{~m}^{2}\right.$ per pixel). Nevertheless, when dividing this rollover drainage area by resolution to assess $L_{\mathrm{H}}$, we find similar values across datasets. Downstream and upstream $L_{\mathrm{H}}$, respectively, are 163 and $116 \mathrm{~m}$ (30 m SRTM-C), 116 and $116 \mathrm{~m}$ (30 m TanDEM-X), 76 and $94 \mathrm{~m}$ (12 m TanDEM$\mathrm{X}), 130$ and $83 \mathrm{~m}(10 \mathrm{~m}$ CoSSC TDX), and 119 and $73 \mathrm{~m}$ (5 m AW3D5). For the 10-30 m TerraSAR-X/TanDEM-X data presented here (Fig. 9b-d), there is a noticeable flattening of the downstream median slopes following the initial increase, indicating that for a 1 to 2 order-of-magnitude range of drainage areas, slope values are very similar in the steeper downstream sub-catchment.

Area-slope plots are complemented by area-curvature (Fig. 10) and curvature-slope (Fig. 11) plots to further illustrate differences related to the channel knickpoint and specific DEMs. The larger curvature variability captured in the $5 \mathrm{~m}$ data is again demonstrated with a larger range of curvature plotted (Figs. 10e and 11e) and larger percentile ranges about the median in each bin (Fig. 10e). Little difference in area-curvature (Fig. 10) is noticeable upstream or downstream in the 10-30 m DEMs. For all DEMs, there appears 

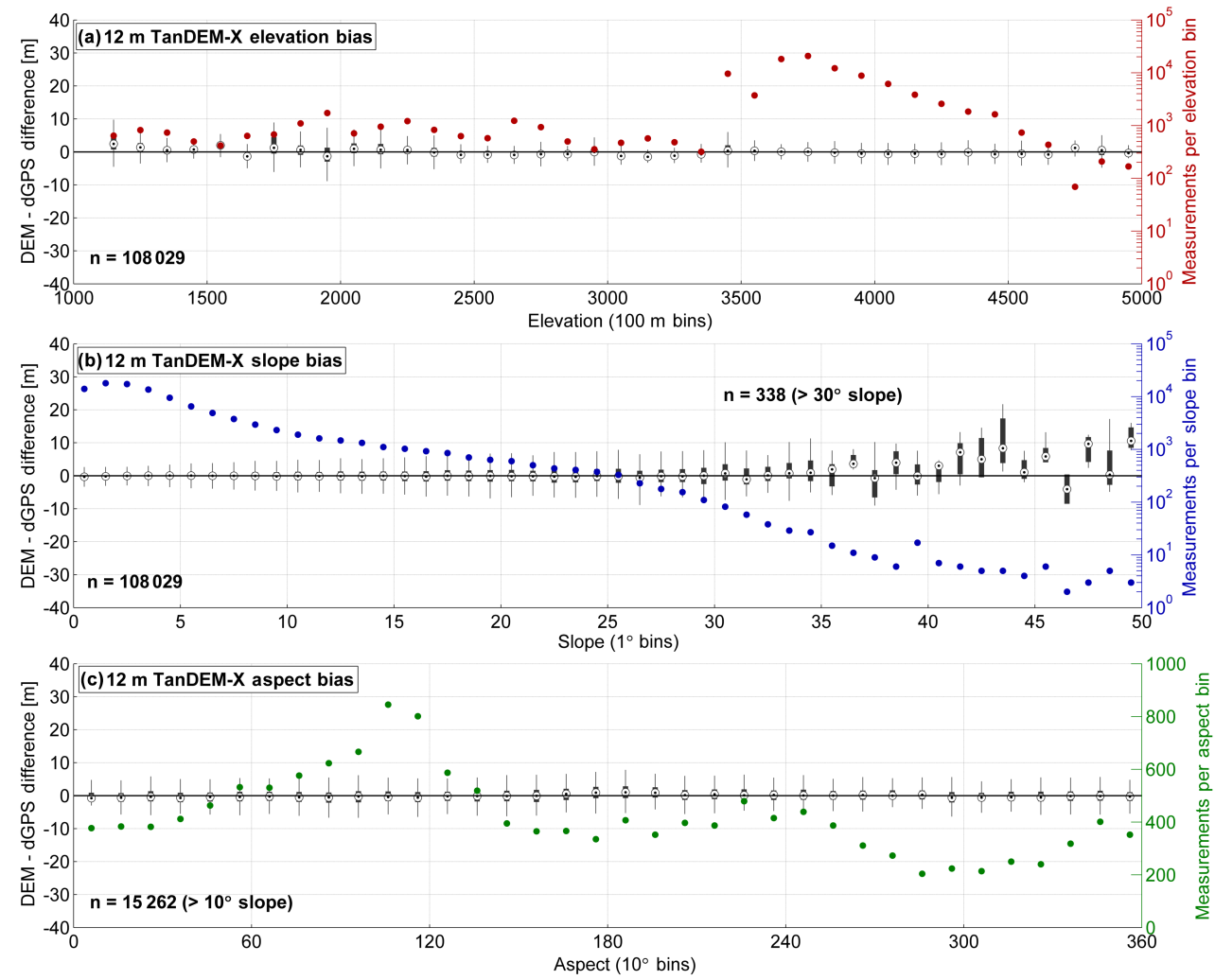

Figure 6. (a) Elevation, (b) slope, and (c) aspect vertical uncertainty bias for the $12 \mathrm{~m}$ TanDEM-X.

to be a scaling break just below the zero-curvature planar inflection point in the concave hillslope realm, perhaps indicating the changeover between diffusive and advective processes resolvable in all DEMs (although again occurring at smaller drainage areas with finer resolution). Plots of slope binned by curvature again indicate similar slopes measured from 30 to $5 \mathrm{~m}$ resolution (Fig. 11). From this analysis, we note that slopes at high convex (negative) and concave (positive) curvatures are similar upstream and downstream, with greater differences on more planar slopes.

\subsection{Two-dimensional fourier analysis}

The calculation of the 2-D DFT for the $30 \mathrm{~m}$ SRTM-C, $12 \mathrm{~m}$ TanDEM-X, and $5 \mathrm{~m}$ AW3D5 provides a quantitative assessment of topographic wavelengths and noise of the DEMs. As detailed in Sect. 3.5., the normalized spectral power is plotted against wavelength for these three datasets at their native resolution (Fig. 12), with the non-normalized 1-D power spectra calculated from Eq. (4) and regression lines used for normalization shown in the Supplement (Fig. S10). In Fig. 12, a 99.9th percentile upper envelope of normalized power displays the similar trends in the distributions, with a distinct spike in normalized power at a wavelength of $\sim 500 \mathrm{~m}$ and smaller secondary peaks above (at $\sim 800 \mathrm{~m}$ ) and below (at $\sim 250 \mathrm{~m}$ ) corresponding to ridge-and-valley structures in the area of the Quebrada Honda. However, what we are more interested in is the presence of a number of high peaks at approximately $10,15,20$, and $40 \mathrm{~m}$ in the AW3D5 plot (with less pronounced expression at 25-35 m), causing a difference of 1 order of magnitude in normalized spectral power scaling (Fig. 12c). These wavelengths correspond to 2-8 pixel steps in the AW3D5 data, indicating a significant high-frequency component in this optical DEM that is not found in the 12 or $30 \mathrm{~m}$ radar-derived datasets.

Statistical tests help further quantify the effect of the high-power spikes in the $5 \mathrm{~m}$ AW3D5 data, given the overall similar shape of the spectral power distribution to the $12 \mathrm{~m}$ TanDEM-X. The two-sample KS test, which measures the difference in the cumulative distribution function (CDF) for each dataset, rejects the null hypothesis that both samples are taken from the same distribution at the $99 \%$ confidence interval with a $p$ value of 0 . These results suggest that the power spectra distributions of AW3D5 and TanDEM$\mathrm{X}$ are significantly different despite similar elevation validation and geomorphic metric results. To better explore how these differences relate to normalized spectral power spikes shown in Fig. 12, we plot the sample quantiles against one another (Fig. 13a). Noted are the 99th, 99.9th, 99.99th, and 99.999th quantiles, representing, respectively, normalized spectral powers of 11.1, 18.4, 33.6, and 106.1 for the AW3D5 data and 7.1, 12.5, 21.3, and 42.1 for the TanDEM-X 

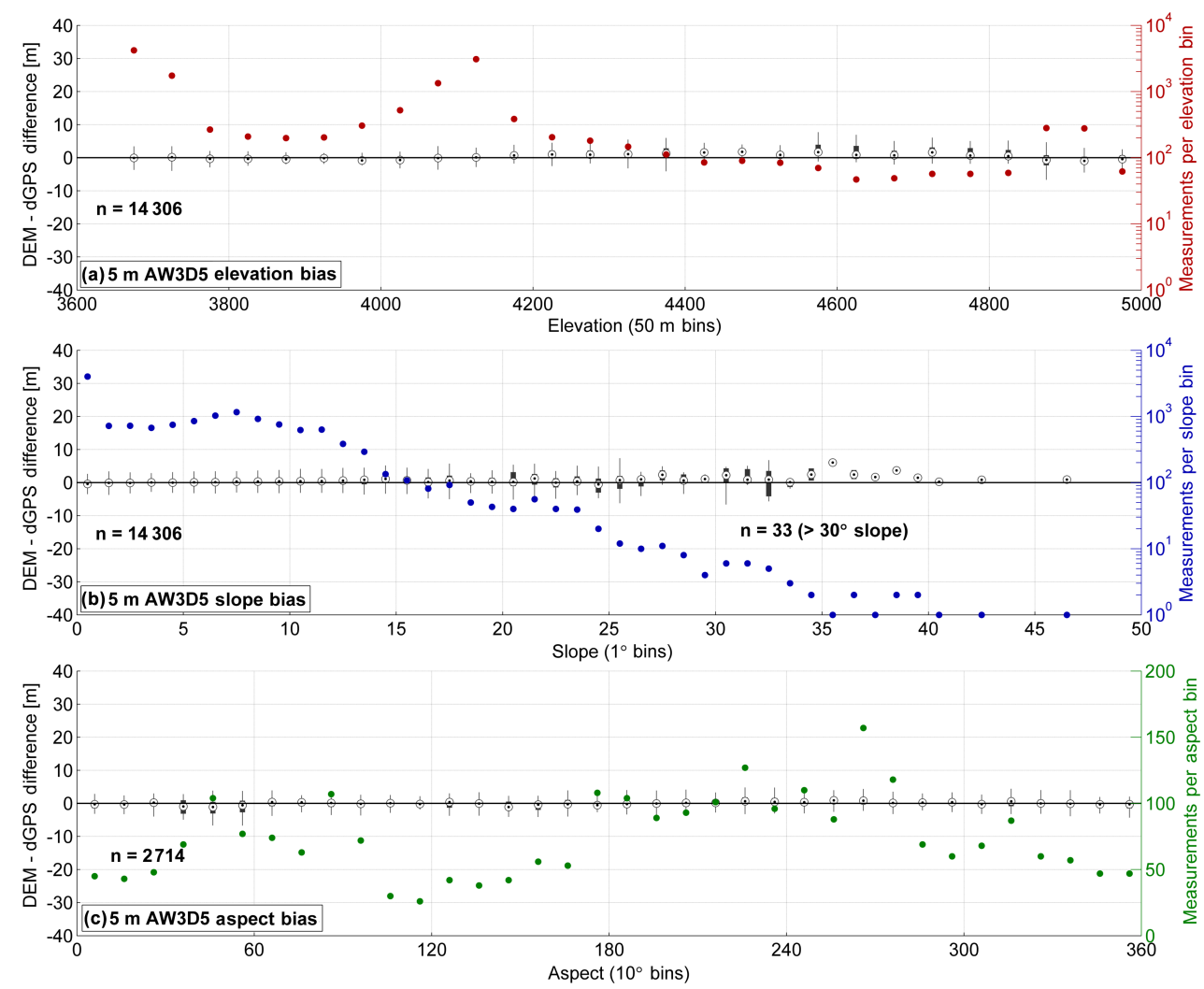

Figure 7. (a) Elevation, (b) slope, and (c) aspect vertical uncertainty bias for the $5 \mathrm{~m}$ AW3D5.

data. Nonlinear excursion from an approximately linear trend towards higher and higher normalized spectral power for the AW3D5 is caused by only a small percentage of DFT elements greater than the 99.99th quantile. For the AW3D5, the values above this quantile represent only 840 DFT elements (of a total $\sim 8.4 \times 10^{6}$ ) and only 210 for the TanDEM-X (of a total $\sim 2.1 \times 10^{6}$ ). Additionally, the inset normalized CDF plot (Fig. 13b) shows that while the median values $(\sim 0.5$ normalized CDF) correspond between the datasets, there is the greatest diversion only at very high and very low spectral powers. Figure 13b provides an additional explanation of why the KS test is unable to reject the null hypothesis. Despite following a similar trend for over $99 \%$ of the distribution, high-frequency (low-wavelength) noise in 2-8 pixel steps causes significant differences in the $5 \mathrm{~m}$ AW3D5.

\section{Discussion}

\subsection{Elevation validation}

\subsubsection{The $30 \mathrm{~m}$ DEMs}

The low quality of the ASTER GDEM2 is readily apparent in the wide uncertainty distribution (Fig. 3a), leading to a $>2 \%$ outlier reduction in measurements used to assess uncertainty, but a SD remaining near $10 \mathrm{~m}$ (Table 2). For over
228000 Australian National Gravity Database station heights with $<1 \mathrm{~m}$ vertical accuracy, Rexer and Hirt (2014) found similar results for the GDEM2, with SD ranging from $7.7 \mathrm{~m}$ in flat terrain to $11.29 \mathrm{~m}$ in mountainous regions. Baade and Schmullius (2016) also found vertical errors of $12-20 \mathrm{~m}$ for the GDEM2, using over 10000 high-accuracy dGPS measurements. Other studies have reported vertical accuracies of 3-9 $\mathrm{m}$ for the GDEM2, but these are often determined with fewer $(<100)$ high-accuracy control points compared with our study using over 300000 dGPS measurements (e.g., Mukherjee et al., 2013; Athmania and Achour, 2014; Bagnardi et al., 2016). Our results further confirm that in a mountainous, non-vegetated region the GDEM2 falls short of the reported vertical accuracy of $8.86 \mathrm{~m}$ (Tachikawa et al., 2011), even when ignoring gross outliers. In addition to the largest vertical uncertainty, the ASTER GDEM2 displays the largest uncertainties with respect to each topographic characteristic (elevation, slope, and aspect) (Fig. S5). An increase in uncertainty is apparent with increasing slopes, indicating overprediction of elevation for the ASTER GDEM2 at higher slopes; however, we also note the decrease in number of measurements at slopes $>30^{\circ}$ (Fig. S5b). The GDEM2 experiences a clear aspect bias with an amplitude of $\sim 5 \mathrm{~m}$ (Fig. S5c), which is lower than the $\sim 50 \mathrm{~m}$ aspect bias reported in far-north glaciated terrain by Nuth and Kääb (2011). The ASTER stack generated for the Pocitos Basin shows im- 

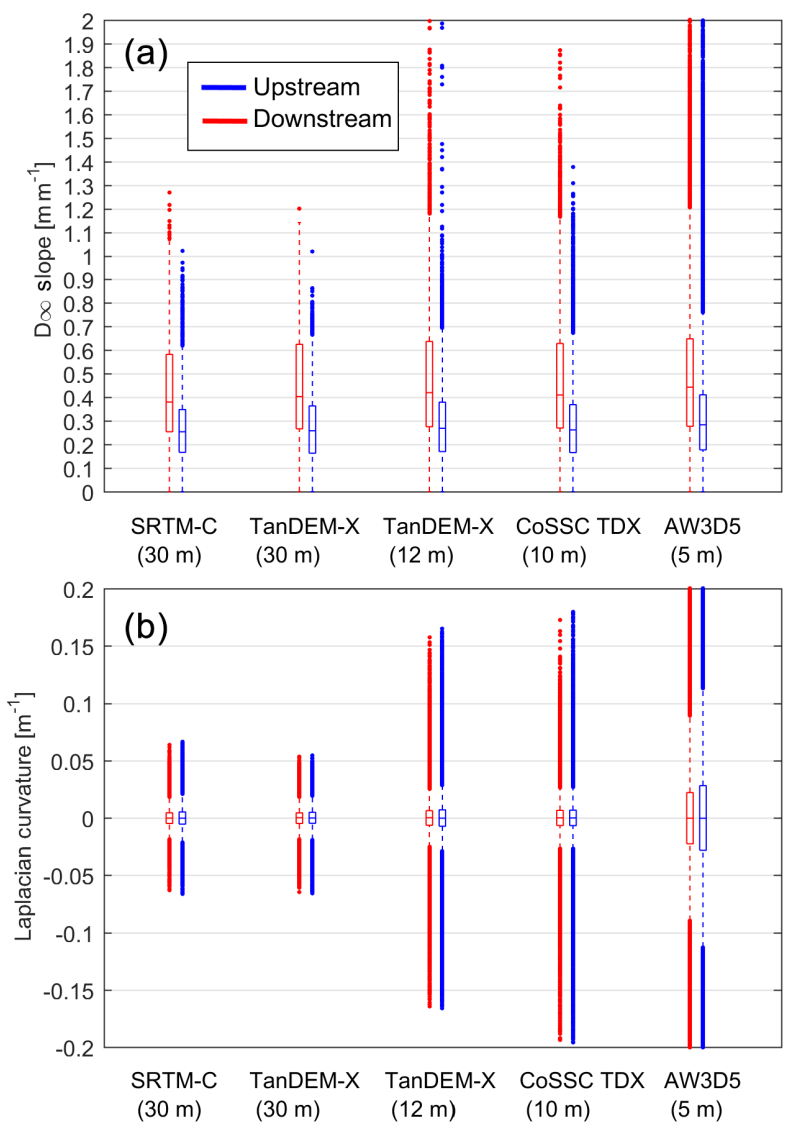

Figure 8. Slope (a) and curvature (b) box plots separated upstream (blue) and downstream (red) for five DEMs. Center line is median, boxes are 25-75th percentile range, dashed whiskers extend to first and 99th percentiles, and all outliers are plotted as points. Note that in cases where the outliers extend out of range of the plots, the points are truncated.

provement, with SD reduced to $6.93 \mathrm{~m}$ and only $0.12 \%$ outlier reduction (Fig. 3b), as well as elimination of the aspect bias noted in the GDEM2 (Fig. S6c). This stack also represents an improvement over individual ASTER L1A stereopair DEMs with reported accuracies of 7-60 m (e.g., Toutin and Cheng, 2001; Hirano et al., 2003; Kääb, 2005; Nuth and Kääb, 2011). Despite this, the ASTER stack was deemed of insufficient quality for geomorphometry after visual inspection revealed remaining noise on hillslopes and channel elevation profiles, complicating slope and curvature measurements.

The SRTM-C, $30 \mathrm{~m}$ TanDEM-X, and AW3D30 have narrow vertical uncertainty distributions, with SDs of 3.33, 2.42, and $2.81 \mathrm{~m}$, respectively, and $<0.04 \%$ reduction in measurements from $\pm 30 \mathrm{~m}$ outlier removal (Table 2 ). While elevation accuracy has not been previously reported for the AW3D30 or $30 \mathrm{~m}$ TanDEM-X, our results indicate that these datasets exceed mission specifications of $<5 \mathrm{~m}$ for the AW3D30 (Tadono et al., 2014) and $<10 \mathrm{~m}$ for the TanDEM-X (Wessel,
2016; Baade and Schmullius, 2016). Most elevation accuracy reporting for the SRTM DEMs has centered on the $30 \mathrm{~m}$ X-band and $90 \mathrm{~m} \mathrm{C}$-band products (e.g., Rexer and Hirt, 2014; Mukherjee et al., 2013; Kolecka and Kozak, 2014), and not the 2014 globally released (previously only USA) $30 \mathrm{~m}$ C-band DEM used here. In exception to this, Baade and Schmullius (2016) report vertical accuracy of 8-9 $\mathrm{m}$ for the $30 \mathrm{~m}$ SRTM-C, including outliers. Our SRTM-C (filtered) results are in close agreement with the $3.64 \mathrm{~m}$ accuracy found using 19 high-accuracy ground measurements for a steep volcano (Bagnardi et al., 2016) and less than the $8 \mathrm{~m}$ accuracy versus a control DEM on another volcano (Kervyn et al., 2008). Hofton et al. (2006) report a vertical SD of 2-7 m for low-vegetation regions in the USA for the SRTM-C versus high-accuracy lidar data. For the $30 \mathrm{~m}$ SRTM-C our results exceed the $6.2 \mathrm{~m}$ vertical accuracy found by Rodriguez et al. (2006) for dGPS tracks across South America.

These three high-quality $30 \mathrm{~m}$ DEMs exhibit no apparent biases with respect to elevation or aspect, and all show smaller ranges of uncertainties than the ASTER GDEM2. This is especially pronounced in the TanDEM-X, with the narrowest uncertainty ranges plotted (Fig. S7). Vertical uncertainty at higher slopes for the SRTM-C show overestimation of elevation, in agreement with the findings of Shortridge and Messina (2011). Conversely, the AW3D30 (Fig. S4b) and TanDEM-X (Fig. S7b) indicate lower uncertainties (but still increasing) at these higher slopes. Previous studies suggesting SRTM-C biases related to slope and aspect (e.g., Berthier et al., 2006, 2007; Van Niel et al., 2008; Shortridge and Messina, 2011) cannot be discounted by our findings, but we expect lower uncertainties with respect to slope in our non-glaciated, vegetation-free study area, where effects like radar penetration (e.g., Rignot et al., 2001; Becek, 2008; Gardelle et al., 2012) are minimal. Radar-associated biases are unexplored for TanDEM-X and are not apparent in our vegetation-free study area. These effects are also absent from the AW3D30 as this DEM was generated through optical methods by stacking of ALOS PRISM tri-stereopairs.

Results of $30 \mathrm{~m}$ global DEM elevation validation indicate the high quality of height information from SRTM-C, TanDEM-X, and AW3D30. ASTER GDEM2 is a far noisier dataset, which complicates geomorphic analyses requiring accurate slope and curvature calculations (e.g., Kervyn et al., 2008; Fisher et al., 2013; Pipaud et al., 2015). This noise is persistent, although slightly reduced, in the manually generated ASTER stack. Despite its low SD, visual inspection of the AW3D30 revealed its inadequacy for assessing geomorphic metrics. In addition to step-like artifacts on hillslopes, likely caused by resampling at the Japan Aerospace Exploration Agency (JAXA), this dataset also had numerous holes and hillslope artifacts caused by errors in optical DEM generation. Similar to the optically generated ASTER DEMs, these errors are caused by low contrast and cloud cover that hinder stereogrammetric methods. The $30 \mathrm{~m}$ TanDEM-X performed best in terms of agreement with dGPS measurements 

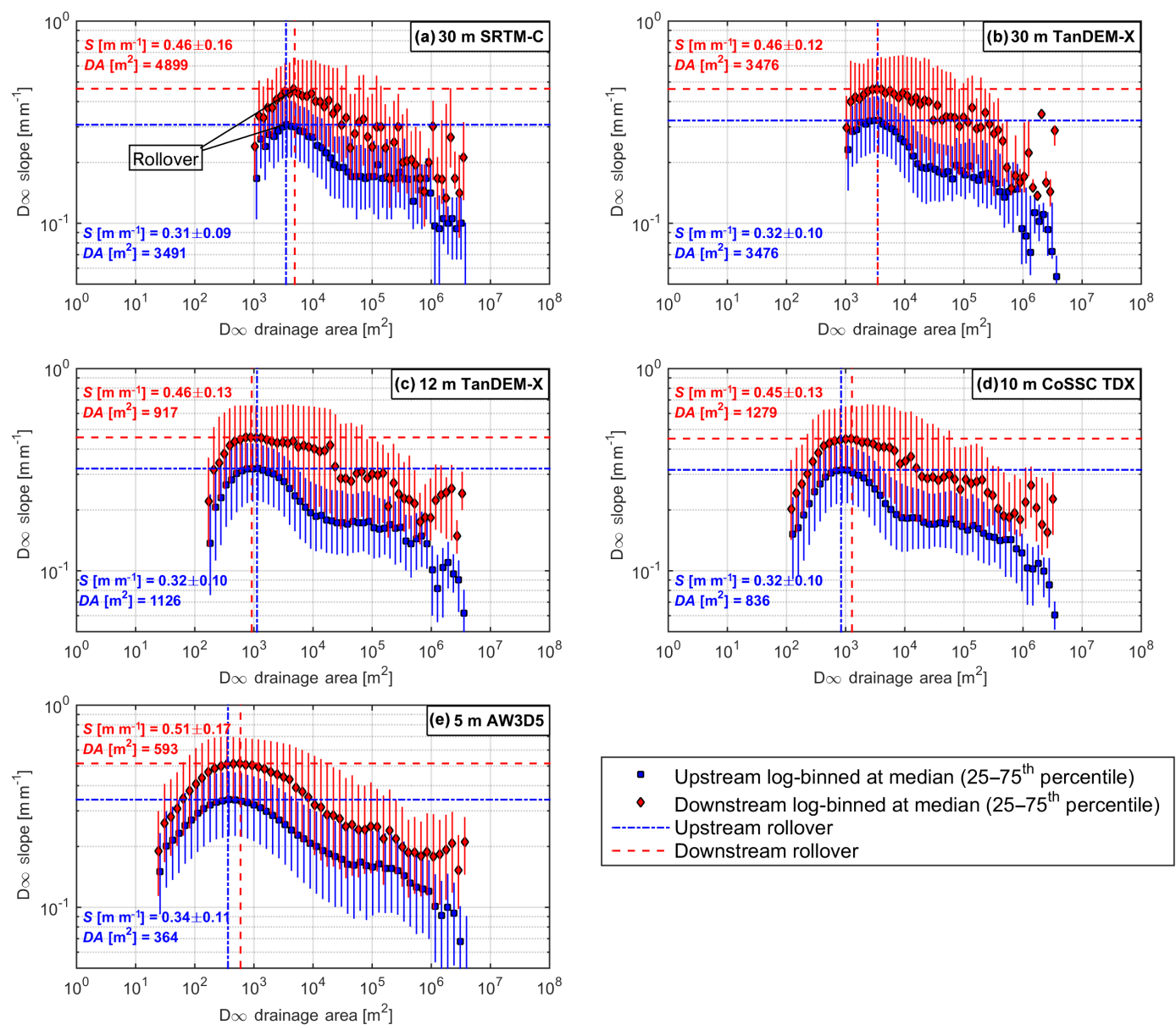

Figure 9. Logarithmically binned drainage area versus median slope with 25-75th percentile range of slopes indicated for (a) SRTM-C $30 \mathrm{~m}$, (b) TanDEM-X $30 \mathrm{~m}$, (c) TanDEM-X $12 \mathrm{~m}$, (d) CoSSC TDX $10 \mathrm{~m}$, and (e) AW3D5 5 m DEMs. Analysis separated downstream (red diamonds) and upstream (blue squares) of the knickpoint. Rollover drainage area demarcating approximate hillslope-to-valley transition, after which all subsequent slope values are less, is marked by vertical dashed line with slope at this bin marked by horizontal dashed line. Mean \pm SD of slope $(S)$ at the rollover drainage area bin (DA) recorded upstream and downstream. Plots are truncated to provide better visualization at very high drainage areas with low slopes.

and limited biases with respect to elevation, slope, and aspect. As the SRTM-C performed comparably well in terms of elevation accuracy, both of these $30 \mathrm{~m}$ datasets were selected for geomorphometric analysis.

\subsubsection{The 5-12 m DEMs}

Similar to the AW3D30, the vertical uncertainty for the AW3D5 exceeds the mission standard of $<5 \mathrm{~m}$ (Tadono et al., 2014). The low SDs of 2.02, 3.83, and $3.22 \mathrm{~m}$ for our three CoSSC TDX DEMs are in close agreement with reported vertical accuracies of $5.74 \mathrm{~m}$ versus ground control points (Bagnardi et al., 2016), $3.57 \mathrm{~m}$ versus lidar data (Du et al., 2015), and $<2 \mathrm{~m}$ versus laser altimetry (Rossi et al., 2016) for interferometrically generated CoSSC TDX DEMs with resolutions of 5-12 m. Wider, bimodal uncertainty distributions for the CoSSC TDX DEMs covering the Quebrada
Honda and Nevado Queva (2012 and 2013 DEMs in Fig. 4b) are likely related to radar shadowing and layover in steeper terrain. Aspect biases for these single-CoSSC radar DEMs (Figs. S8-S9) were removed in the stacked $12 \mathrm{~m}$ TanDEM$\mathrm{X}$ relying on descending and ascending orbits, which also had a lower SD of $1.97 \mathrm{~m}$, again exceeding mission standards (Wessel, 2016; Baade and Schmullius, 2016).

Good vertical accuracy performance is seen in the stacked $5 \mathrm{~m}$ AW3D5 and stacked $12 \mathrm{~m}$ TanDEM-X product, with both datasets having narrow vertical uncertainty ranges plotted across terrain attributes (Figs. 6-7). While interferometrically generated single-CoSSC TDX DEMs (the same data used to generate the stacked TanDEM-X DEMs) also performed well in terms of vertical accuracy, a single stereogrammetrically generated ALOS PRISM tri-stereopair DEM (the same data used to generate the stacked AW3D DEMs) performed poorly and was not included in further 

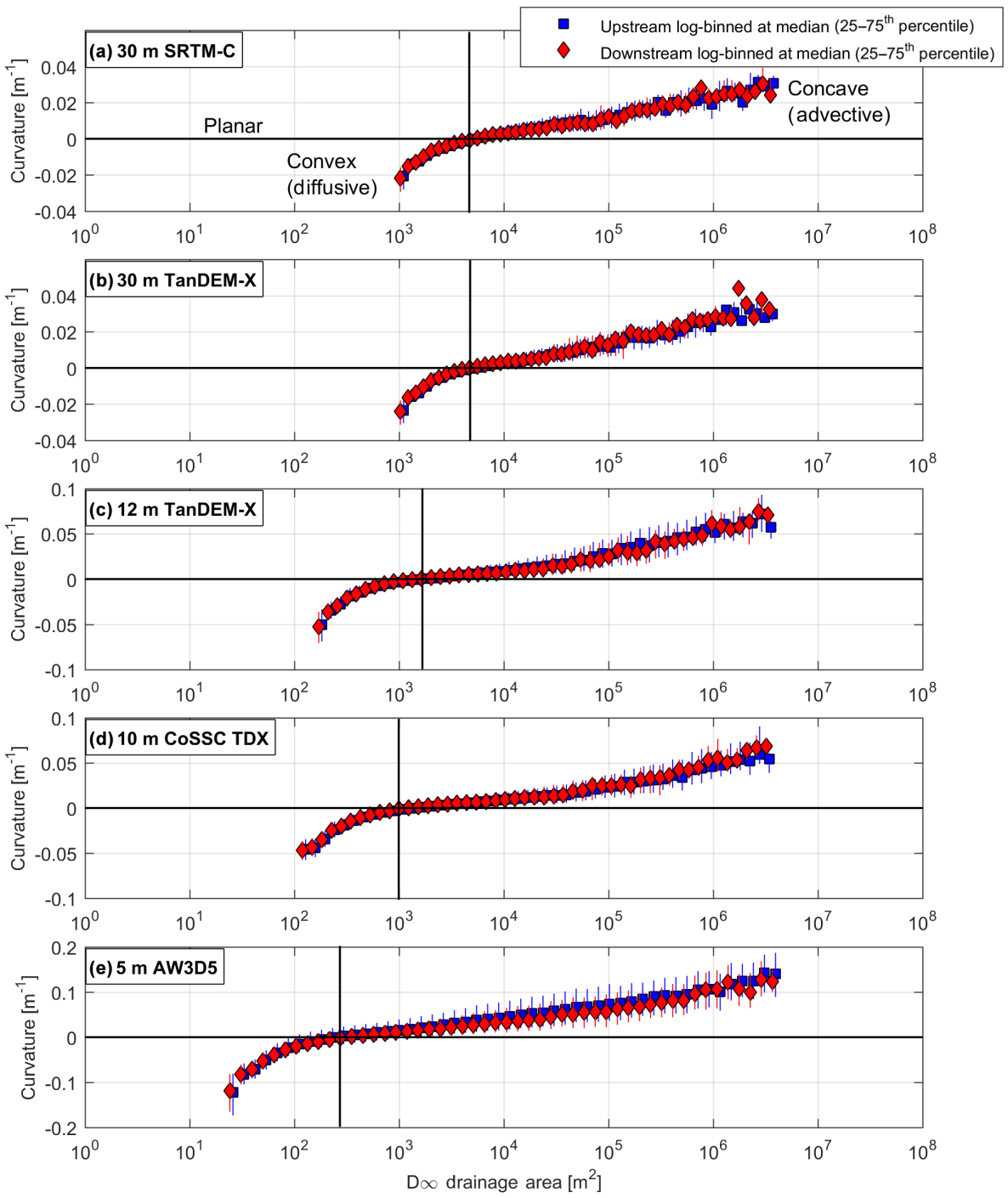

Figure 10. Logarithmically binned drainage area versus median curvature with 25-75th percentile range of curvatures indicated for (a) SRTM-C $30 \mathrm{~m}$, (b) TanDEM-X $30 \mathrm{~m}$, (c) TanDEM-X $12 \mathrm{~m}$, (d) CoSSC TDX $10 \mathrm{~m}$, and (e) AW3D5 $5 \mathrm{~m}$ DEMs. Analysis separated downstream (red diamonds) and upstream (blue squares) of the knickpoint. Greater variability in curvature (larger error bars and greater $y$-axis range) is measured in the $5 \mathrm{~m}$ data. Vertical line marks approximate changeover from diffusive hillslope processes (convex curvature) to advective fluvial processes (concave curvature).

analysis (see Supplement). In conjunction with the improvement seen in our ASTER stack, these results indicate the importance of stacking multiple DEMs from the same data source to improve quality of the final product. This point is emphasized by the elimination of the aspect bias in the stacked $12 \mathrm{~m}$ TanDEM-X. The higher vertical accuracy and more realistic landscape representation of the singleCoSSC TDX radar DEM versus the single ALOS PRISM tri-stereopair DEM points to the greater potential of radar to accurately represent topography (e.g., the high-quality, radar SRTM-C versus the lower-quality, optical ASTER GDEM2).

Elevation accuracy for the higher-resolution DEMs is similar to the high-quality $30 \mathrm{~m}$ DEMs. The close agreement in vertical uncertainty (all $<3.5 \mathrm{~m}$ ) between the highest-quality datasets (30m SRTM-C, 30 and $12 \mathrm{~m}$ TanDEM-X, $10 \mathrm{~m}$ CoSSC TDX, and $5 \mathrm{~m}$ AW3D5) necessitates our geomorphic metric comparisons to better understand the limitations related not only to resolution but also to sensor. Our data show that for a number of DEMs, accurate elevation data are negligibly influenced by resolution at 5-30 m (Vaze et al., 2010), making differences in DEM quality for deriving geomorphic metrics unapparent from the pixel-by-pixel dGPS comparisons and SD metric. 

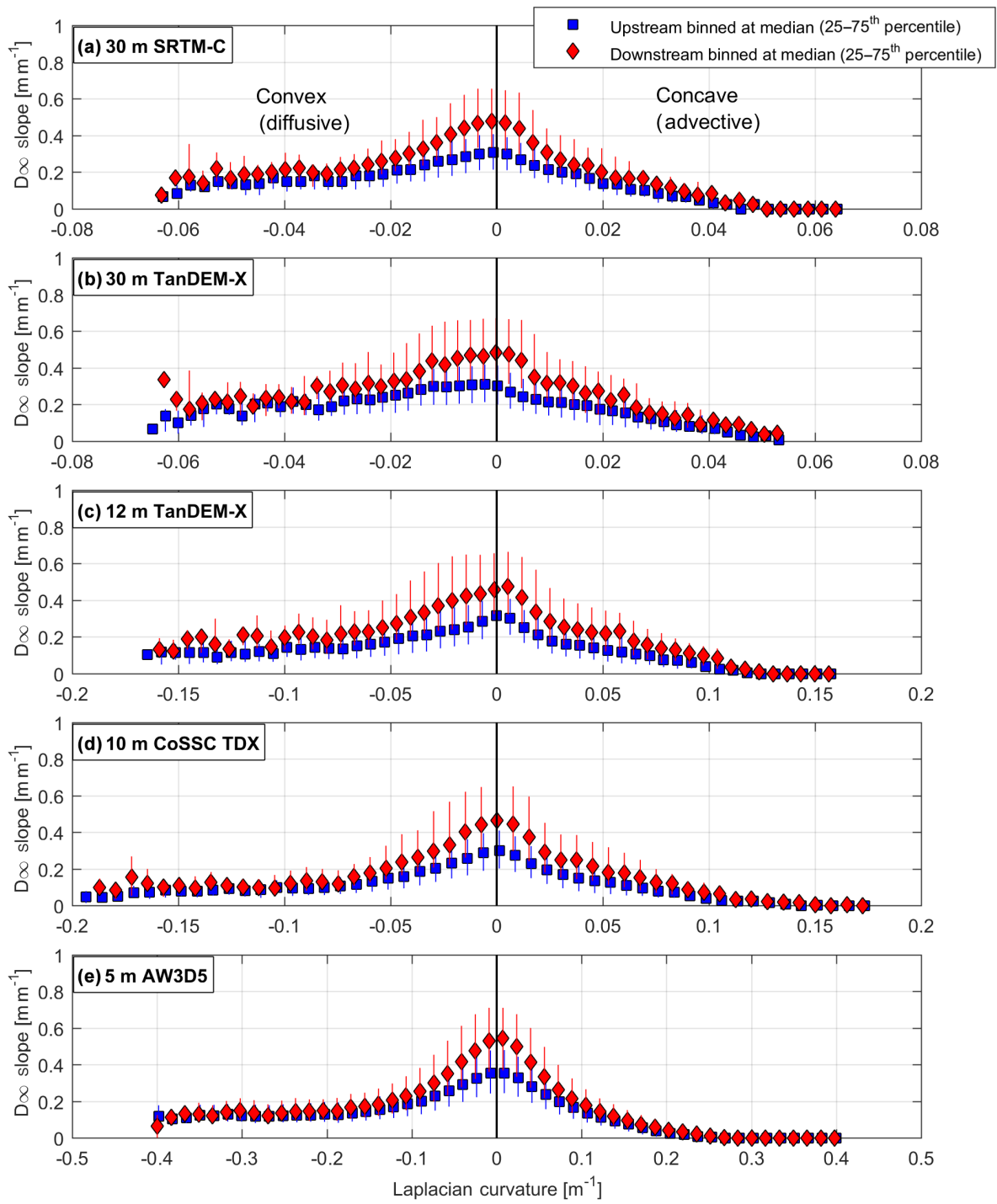

Figure 11. Linearly binned curvature versus median slope with 25-75th percentile range of slopes indicated for (a) SRTM-C 30 m, (b) TanDEM-X $30 \mathrm{~m}$, (c) TanDEM-X $12 \mathrm{~m}$, (d) CoSSC TDX $10 \mathrm{~m}$, and (e) AW3D5 $5 \mathrm{~m}$ DEMs. Analysis separated downstream (red diamonds) and upstream (blue squares) of the knickpoint. Greater variability in curvature is measured in the higher-resolution data as indicated by the growing $x$-axis range. Vertical line marks planar slopes dividing diffusive hillslope processes (convex curvature) to advective fluvial processes (concave curvature).

\subsection{Geomorphometric validation}

\subsubsection{Channel profiles}

The $m / n$ values for the Quebrada Honda trunk correspond well across the datasets ( $30 \mathrm{~m}$ SRTM-C, $10 \mathrm{~m}$ CoSSC TDX, and $5 \mathrm{~m} \mathrm{AW} 3 \mathrm{D} 5$ ) and between the chi plot methods (Table 3). This is despite the fact that the knickpoint causes the channel to plot nonlinearly in chi space using the leastsquares method (Fig. S2), whereas the piece-wise method allows exact fitting (Fig. S3). These values (0.49-0.57) fall well within the range of reported $m / n$ values in a variety of other settings (e.g., Wobus et al., 2006; Kirby and Whipple, 2012; Harel et al., 2016). Testing on the $30 \mathrm{~m}$ DEMs revealed similar $m / n$ values regardless of the elevation noise. For instance, the ASTER GDEM2, which had the largest vertical uncertainty and noisiest appearance, returned $m / n=0.53$ with $R^{2}=0.97$ using the least-squares method, which is identical to the SRTM-C results. The only difference for the higher-resolution datasets is a slightly lower SD (uncertainty) of minimum AICc for piece-wise fitting: $\sim 0.5$ for the $30 \mathrm{~m}$ versus $\sim 0.2$ for the 5 and $10 \mathrm{~m}$ DEMs. Conversely, the coefficients of determination $\left(R^{2}\right)$ from least-squares fitting are nearly identical for all three DEMs.

Differences in $m / n$ values between the datasets are likely caused by differences in channel lengths for the area threshold channel delineation method or by minor differences in 

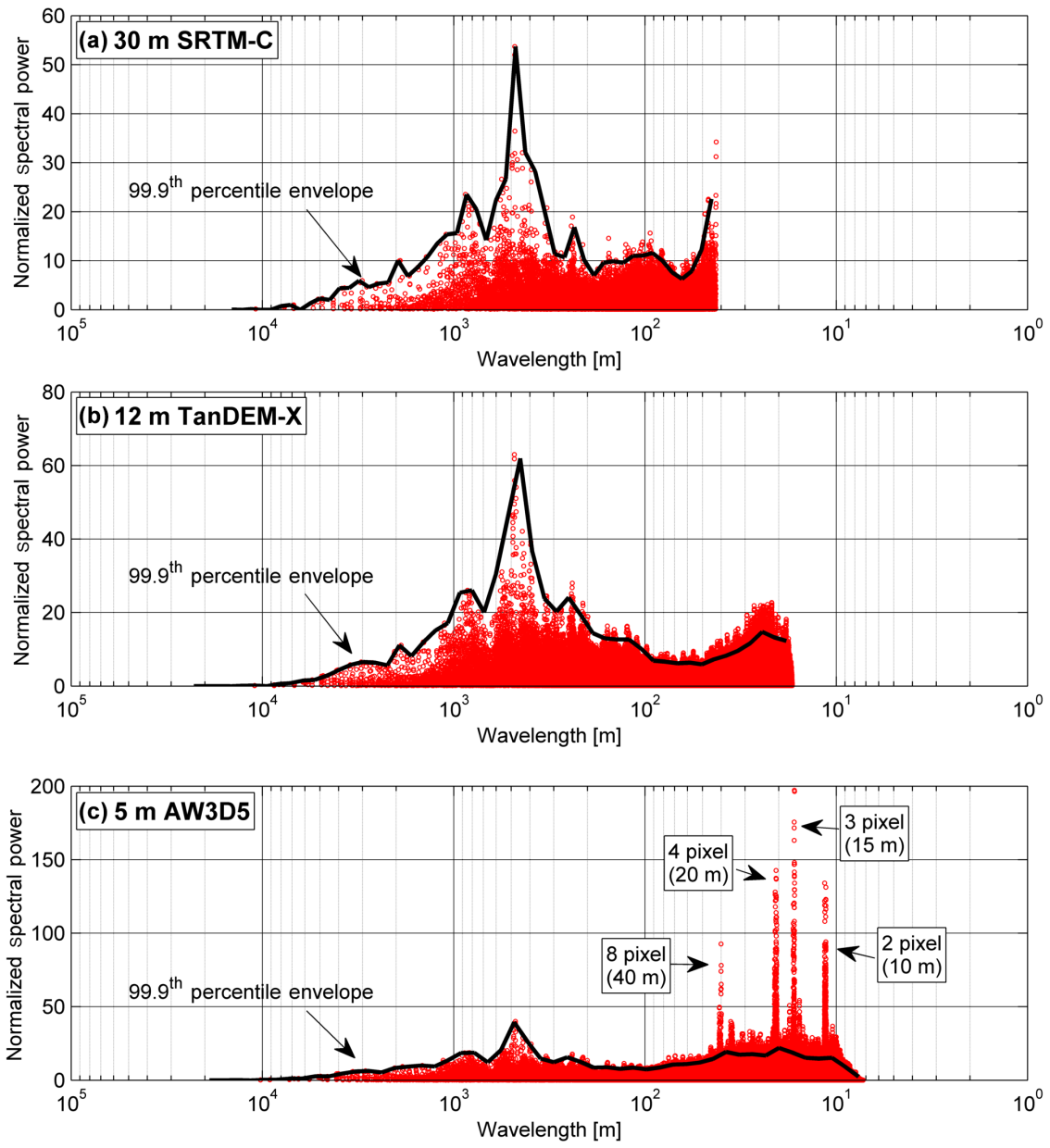

Figure 12. One-dimensional normalized power spectra for (a) $30 \mathrm{~m}$ SRTM-C, (b) $12 \mathrm{~m}$ TanDEM-X, and (c) $5 \mathrm{~m}$ AW3D5 plotted against wavelength (frequency ${ }^{-1}$ ). Wavelength here is equivalent to spatial resolution in pixels. The 99.9th percentile envelope is calculated from 50 logarithmically spaced bins to highlight the peak in spectral power at $\sim 500 \mathrm{~m}$ and the high-frequency (low-wavelength) spikes in the AW3D5 data. These spikes correspond to 2-8 pixel (10-40 m wavelength) steps in this $5 \mathrm{~m}$ DEM and cause a difference of 1 order of magnitude in $y$ scaling for plot (c).

exact channel placement downstream in the valley bottom. Nonetheless, the $m / n$ values calculated using either chi plot method (least-squares or piece-wise fitting) are comparable regardless of DEM resolution (or noise, as indicated by the ASTER GDEM2 results), indicating the ability of all satellite-derived DEMs tested to resolve the valley bottom in our steep test catchment. This result only holds for relatively simple channel shapes, like the Quebrada Honda, whereas the inclusion of tributaries and more complex settings may warrant further testing and the preferred use of the statistically robust piece-wise fitting method (Mudd et al., 2014). Consideration of different channel lengths and changes in $m / n$ may be an important factor when using the ASTER GDEM2 for chi plot analysis, as this dataset has demonstrated excessive channel foreshortening over long stretches (Fisher et al., 2013). Regardless, these results indicate that channel profile $m / n$ analysis for mapping $k_{\mathrm{sn}}$ at
$>1 \mathrm{~km}^{2}$ scales, where minor differences related to channel head placement can be ignored (e.g., Grieve et al., 2016c), is readily achieved for open-access $30 \mathrm{~m}$ DEMs.

\subsubsection{Hillslopes}

The large increase in slope and curvature variability (outlier ranges; Fig. 8) with finer resolution - also demonstrated in Pipaud et al. (2015) - can be explored in a map view of curvature colored by a $\pm 3 \sigma$ range for each DEM (Fig. 14). As the second derivative of elevation, curvature was selected for map view plots to highlight variability in elevation and slope (first derivative), as elevation errors propagate to higher derivatives. While the curvature signals of large ridges and narrow valleys are readily identified, although low in magnitude on the $30 \mathrm{~m}$ DEMs (Fig. 14a-b), many more features become apparent at higher resolutions. The $12 \mathrm{~m}$ TanDEM$\mathrm{X}$ (Fig. 14c) and $10 \mathrm{~m}$ CoSSC TDX (Fig. 14d) DEMs appear 


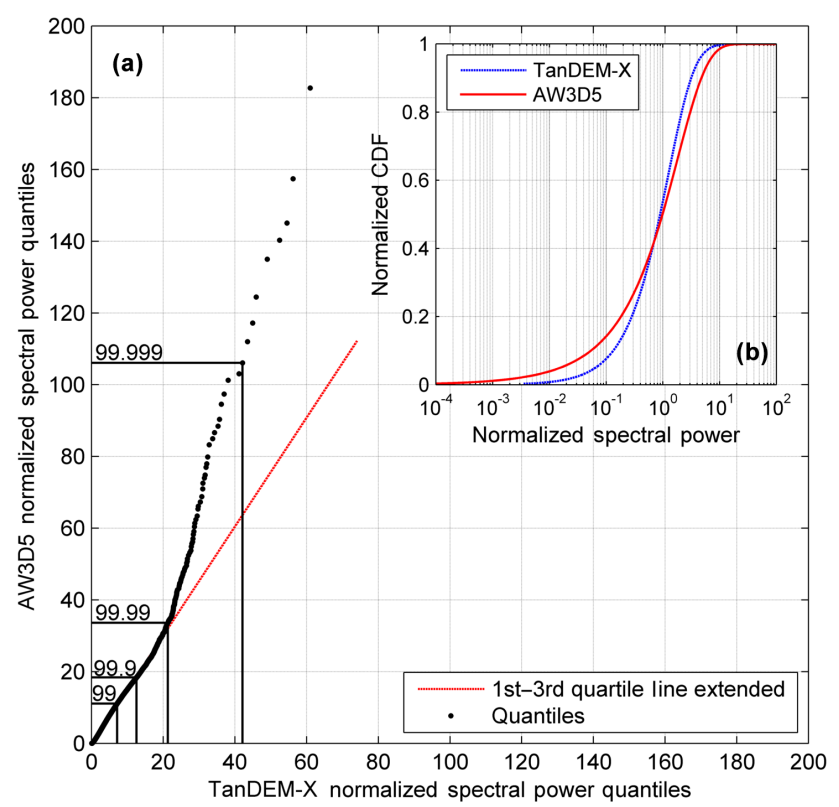

Figure 13. Statistical analysis of 1-D normalized spectral power shown in Fig. 12, with (a) QQ plot of $12 \mathrm{~m}$ TanDEM-X versus $5 \mathrm{~m}$ AW3D5 and (b) normalized CDF of normalized spectral power. Quantiles are plotted from 0.1 to 99.9998 in 0.0001 step sizes. The 99th, 99.9th, 99.99th, and 99.999th quantiles are noted for both datasets in panel (a) and the linear trend connecting the first and third quartiles is projected to display the diversion in the trend above the 99.99th quantile. We note the steeper than one-to-one trend in the data, demonstrating the higher spectral powers that dominate the AW3D5 signal.

similar (and have a similar $\pm 3 \sigma$ range), although in the $10 \mathrm{~m}$ CoSSC TDX we note some striping becoming apparent in the second derivative of elevation, likely from interferometric processing of this single radar pair (Pipaud et al., 2015). For the $12 \mathrm{~m}$ TanDEM-X, the hillslopes appear smooth, separated by high-magnitude peaks at ridge crests and valley bottoms. The $5 \mathrm{~m}$ AW3D5 (Fig. 14e) shows the greatest variability, with sharp ridges and narrow valleys becoming obscured by other high curvatures (and thus high slopes) measured across the landscape. The cause of this may be the large number of rocky outcrops visible throughout the area in the $2.5 \mathrm{~m}$ panchromatic, nadir ALOS PRISM optical data (Fig. 14f). However, previous work suggests that large outliers in curvature can indicate DEM error and should be carefully considered (Sofia et al., 2013; Pipaud et al., 2015).

In Fig. 15, we explore this variability further with a map view of a hillshade image for the $5 \mathrm{~m} \mathrm{AW3D5}$ and $12 \mathrm{~m}$ TanDEM-X, in an area with less rocky outcrops, alongside the same area as viewed on the $2.5 \mathrm{~m}$ PRISM scene (the same data used to generate the AW3D5 DEM). While ridges and valleys are similar and the debris flow gully in the center can be identified on each DEM, there is a clear difference in smoothness between the optical (AW3D5) and radar (TanDEM-X) datasets. This is exactly the noise identified in our 2-D DFT analysis, which demonstrated spikes in spectral power in 2-8 pixel steps in the AW3D5 (Fig. 12c). Furthermore, it is this high-frequency, low-wavelength noise that causes the greater number of slope outliers and higher variability in curvature measurements, despite representing only a small $(0.01 \%)$ fraction of the power spectrum (Fig. 13). In other environments, it could be the case that this noise is caused by animal burrowing activity, tree throw, or some other high-frequency geomorphic process (e.g., Roering et al., 2010); however, it is clear in the optical data that no such processes are operating in this smooth, highly diffusive, vegetation-free environment. Rather, this error is from optical DEM generation and stacking. Such high-frequency noise was also present in the optical ASTER stack and GDEM2, as well as in the ALOS PRISM tri-stereopair, RapidEye, and SPOT6 DEMs, all manually generated via stereogrammetry but not used for further analysis (see Supplement for details on these datasets). Conversely, the radar-derived $12 \mathrm{~m}$ TanDEM-X provides a much more realistic representation of the landscape, despite a coarser resolution.

One important distinction to make with slope and curvature measurements is the window size used for calculation as differences may not only be related to the different sensors but also to the different resolutions. By using an equally sized nine-cell window $(3 \times 3)$ across the datasets, we are measuring different length scales. Numerous authors (e.g., Albani et al., 2004; Sofia et al., 2013) point this effect out with regard to elevation error propagation. To test this, we bilinear resampled the $5 \mathrm{~m}$ AW3D5 to 10 and $30 \mathrm{~m}$ and examined the slope and curvature distributions compared to the $12 \mathrm{~m}$ TanDEM-X and $30 \mathrm{~m}$ SRTM-C. By resampling the $5 \mathrm{~m}$ data to the coarser resolutions, we are essentially changing the length scale over which the derivatives are calculated (still in a nine-cell window). Our results show that with coarsening resolution the $5 \mathrm{~m}$ AW3D5 still shows high-frequency noise, particularly with respect to curvature, but overall they become increasingly similar to TanDEM-X and SRTM-C (Fig. S11). This result indicates that higher-resolution data captures more information even when measuring over the same length scale as coarser data. However, we demonstrate with the Fourier analysis that, in this case, the additional information is just sensor-related noise.

Although curvature measurements may differ widely depending on DEM resolution (and quality), it is clear from our analysis that slope measurements are less sensitive. All DEMs display a broad changeover between dominantly hillslope and dominantly fluvial processes, indicated by a wide area of inflection at the first rollover in area-slope plots, occurring at comparable slope values across datasets (Fig. 9). This stands in contrast to other studies using lidar DEMs, which show a very narrow changeover at DEM resolutions of 1-5 m (Tarolli and Dalla Fontana, 2009; Tseng et al., 2015). However, these studies were based in much wetter environments, where fluvial processes may act to increase this contrast. It is likely the case that this hillslope-to-valley 


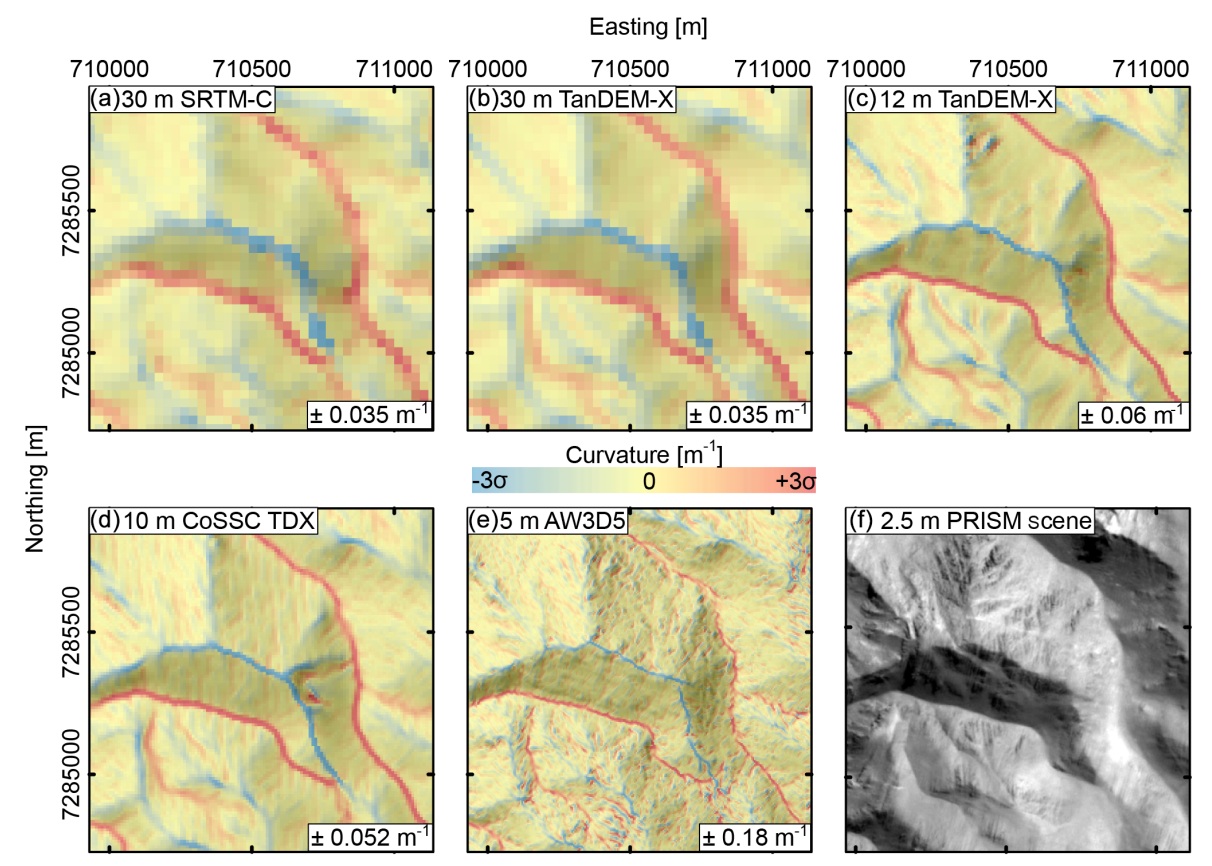

Figure 14. Map view of curvature from a section of the Quebrada Honda overlain on hillshade for (a) $30 \mathrm{~m}$ SRTM-C, (b) $30 \mathrm{~m}$ TanDEM-X, (c) $12 \mathrm{~m}$ TanDEM-X, (d) $10 \mathrm{~m}$ CoSSC TDX, and (e) $5 \mathrm{~m}$ AW3D5. Curvatures colored by a $\pm 3 \sigma$ range to emphasize the high values, with the color bar range noted for each DEM in the lower right. Note the striping present in the CoSSC TDX (d) and the large variability measured in the AW3D5 (e), which may be explained by the rocky outcrops apparent in the ALOS PRISM optical data for this area (f).

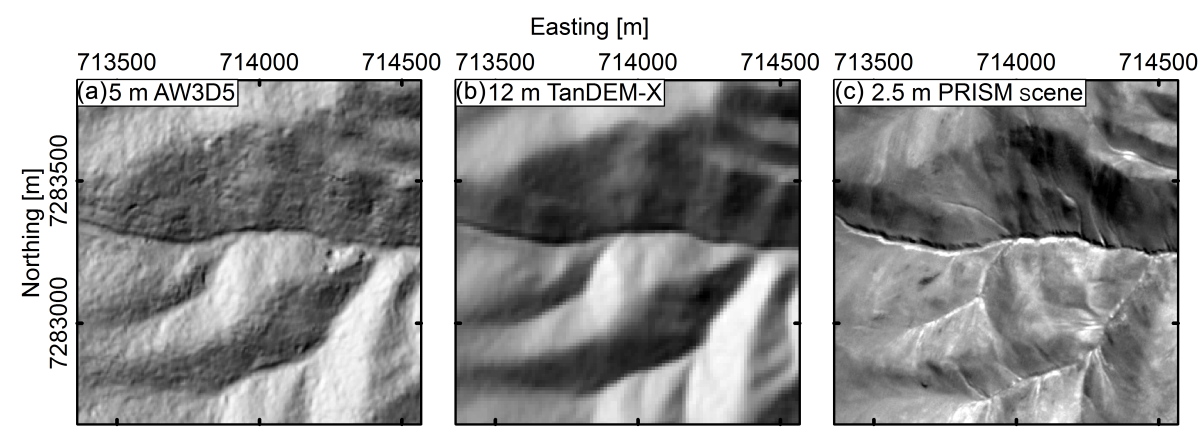

Figure 15. Hillshade view from a section of the Quebrada Honda with few rocky outcrops for (a) $5 \mathrm{~m}$ AW3D5 and (b) $12 \mathrm{~m}$ TanDEM-X, alongside (c) $2.5 \mathrm{~m}$ ALOS PRISM optical scene (nadir view). Ridges, valleys, and central debris flow gully are well represented by both DEMs; however, the high-frequency noise throughout the $5 \mathrm{~m}$ data does not correspond to pit and mound topography in the optical scene.

changeover is highly dependent on environmental conditions and typically occurs over a much larger range, even in the same conditions, due to local complexities at small $\left(\sim 1 \mathrm{~km}^{2}\right)$ scales. The more pronounced difference in slope values in the $10^{4}-10^{5} \mathrm{~m}^{2}$ drainage area range (Fig. 9), may indicate the increased influence of landsliding and other mass-wasting processes in the steeper downstream catchment (Tseng et al., 2015). The flattening of downstream slope values in the TanDEM-X data in this range (Fig. 9b-d) also points to a change in geomorphic processes to more mass wasting in the steeper downstream catchment, further indicating the high quality of this data at resolutions of $10-30 \mathrm{~m}$. In areacurvature and curvature-slope plots (Figs. 10 and 11), we show a greater range of curvature measured with finer resolution, yet slope values in Fig. 11 remain comparable regardless of resolution. Furthermore, Fig. 11 demonstrates that the $0.1-0.2 \mathrm{~m} \mathrm{~m}^{-1}$ magnitude difference in slope measurements upstream and downstream of the knickpoint (Fig. 9) peaks on near-planar hillslopes (zero curvature). Hence, while valley bottoms (highly concave) and hilltops (highly convex) may have small differences in slope and curvature upstream and downstream of the knickpoint in the Quebrada Honda, the intervening hillslopes represent much of the erosional signal in the topography in this landscape.

Interestingly, the horizontal $L_{\mathrm{H}}$ measured in area-slope plots differs little upstream, downstream, and between 
datasets. Agreement in $L_{\mathrm{H}}$ between DEMs indicates that even the coarser (and noisier) DEMs are capable of measuring this key landscape metric. With a mean of $109 \pm 26 \mathrm{~m}$ $(1 \sigma), L_{\mathrm{H}}$ results are within the range (though on the high side) reported in the literature using this technique (e.g., Montgomery and Foufoula-Georgiou, 1993; Roering et al., 2007; Tarolli and Dalla Fontana, 2009; DiBiase et al., 2012; Grieve et al., 2016a). The higher $L_{\mathrm{H}}$ compared with other studies may be caused by the fact that the arid Central Andean Plateau, with low precipitation and little fluvial erosion (Bookhagen and Strecker, 2008, 2012), emphasizes diffusive hillslope processes. This, in turn, leads to longer hillslope measurements compared to studies in less-arid regions (e.g., Roering et al., 2007).

Given the presence of a knickpoint, we expect longer hillslopes in the gently sloped upstream catchment, whereas our data demonstrate equally long hillslopes in the steeper downstream section. This result may be caused by the graphical selection of a rollover value in area-slope plots, which have known deficiencies in assuming uniform basin shape at these scales (Grieve et al., 2016a). However, it could be that upstream and downstream $L_{\mathrm{H}}$ are in fact similar. In that case, steeper slopes downstream given the same curvature and drainage area (Figs. 9 and 11) would be compensated for by greater relief rather than longer hillslopes in order to maintain steady state of hillslopes with respect to changing base levels caused by the migrating knickpoint. Relief measured across DEMs in a $100 \mathrm{~m}$ radius (consistent with the measured $L_{\mathrm{H}}$ ) is $\sim 35 \mathrm{~m}$ greater downstream, indicating that this hypothesis is a possible explanation for the similar $L_{\mathrm{H}}$.

The relative steady state of the upstream and downstream portions of the catchment would be surprising given the presence of a migrating knickpoint, which should affect erosion rates. However, in this dominantly diffusive environment there is little advection via fluvial erosion to disturb the landscape. This hypothesis allows hillslopes to adjust to changing base levels as the knickpoint migrates primarily during short pluvial periods on the Puna de Atacama Plateau (e.g., Trauth et al., 2000; Bookhagen et al., 2001; Luna et al., 2017). Although the hillslopes may adjust quickly to the changing base level caused by a migrating knickpoint, hilltop curvature should keep pace with erosion for much longer (Hurst et al., 2012). Despite this, it has been suggested that at resolutions $\geq 5 \mathrm{~m}$, DEMs are unable to capture the fine variability of these curvature measurements (Clubb et al., 2016). Recent work by Grieve et al. (2016c) suggests that for highaccuracy DEMs, the resolution chosen for geomorphometric analysis should depend on how broad features such as ridges and valleys are and whether that resolution can capture variations in these regions.

Attempts to examine this hilltop signal with 27 manually selected subbasins from the $5 \mathrm{~m}$ AW3D5 and $12 \mathrm{~m}$ TanDEM$\mathrm{X}$ data were complicated by transient landscape features in the Quebrada Honda. While a number of steep subbasins can be found downstream of the knickpoint, some of these basins appear to have downstream steepened sections and upstream gently sloped sections. This is indicated by channel steepness values decreasing moving up-valley from the subbasin outlets downstream of the knickpoint (Fig. 2a). It is possible that the trunk knickpoint signal has yet to reach the higher portions of these catchments given the low rate of fluvial erosion on the Puna de Atacama Plateau. Thus, only a limited number of sharper (more convex) hilltop measurements adjusted to the knickpoint are available to analyze subbasin transient adjustment, which is further limited by the number of measurements available (number of pixels making up a hilltop) as resolution decreases. Furthermore, many of these hilltops are not soil-mantled (many rocky outcrops are visible in optical data) and are thus unusable for hilltop curvature measurements (Hurst et al., 2012).

Taken together, results of our study indicate that despite having low vertical uncertainties, DEMs at resolutions of 5$30 \mathrm{~m}$ may not all be sufficient for deriving hillslope-scale geomorphic metrics, especially curvature. This is particularly true for optical DEMs (ASTER and AW3D5), which suffer from high-frequency noise that complicates slope and curvature assessments. Conversely, radar-derived DEMs provide a more realistic representation of the landscape, even in the case of single-CoSSC TDX DEMs, in agreement with Pipaud et al. (2015). While stacking further improves DEM quality (e.g., TanDEM-X DEMs), all DEMs were capable of accurate slope and hillslope length measurements regardless of resolution (or of noise in the case of the AW3D5). Conversely, differences in curvature measurements (particularly outliers) were distinctly dependent on resolution. These results are in agreement with Grieve et al. (2016c), but we emphasize that apparent differences in extracted geomorphic metrics at different resolutions are not only the result of the resolution tested - as in the resampled lidar DEMs of Grieve et al. (2016c) - but also the original sensor biases and multistep processing required to get the data in usable, gridded format. Our results lead us to conclude that the potential of high-accuracy, satellite-derived DEMs in geomorphometry and tectonic geomorphology for exploring transient responses and equilibrium adjustment of large $\left(10-100 \mathrm{~km}^{2}\right)$ catchments remains high; however, $1-5 \mathrm{~m}$ lidar data with realistic landscape representation may still be necessary to assess fine-scale differences in hillslope processes.

\section{Conclusions}

We were able to determine the elevation accuracy of the current generation of global $30 \mathrm{~m}$ digital elevation models (DEMs) by using a 307509 -measurement differential GPS (dGPS) dataset from the high-elevation, vegetationand cloud-free southern Central Andean Plateau (Puna de Atacama). Results indicate the high quality of the SRTMC, TanDEM-X, and ALOS World 3D $30 \mathrm{~m}$ DEMs, with fewer no-data voids and fewer step-like hillslope artifacts in 
the SRTM-C and TanDEM-X DEMs. Furthermore, we have demonstrated the ASTER products' lower quality even after weighted stacking of eight meticulously generated raw L1A DEMs. We extended this analysis to the $12 \mathrm{~m}$ TanDEM-X DEM and demonstrated the very high quality of this dataset. In addition, we assessed the vertical accuracy of a single manually generated CoSSC TerraSAR-X/TanDEM-X $10 \mathrm{~m}$ DEM and the $5 \mathrm{~m}$ ALOS World 3D. With the exception of the ASTER data, all DEMs had vertical accuracy below $4 \mathrm{~m}$. Our dGPS dataset also allowed us to explore the terrain elevation, slope, and aspect vertical biases of these DEMs. For our $30 \mathrm{~m}$ DEMs, we found little evidence of error biases in the SRTMC, TanDEM-X, and ALOS World 3D and only minor aspect biases with the ASTER GDEM2. The $12 \mathrm{~m}$ TanDEM-X performed exceptionally well across all terrain attributes over a large area. The $5 \mathrm{~m}$ ALOS World 3D performed comparably well to the TanDEM-X, although over a much smaller area. More future measurements from higher slopes $\left(>30^{\circ}\right)$ would allow a fuller assessment of the previously described DEM errors on steeper topography but are limited by dGPS measuring capabilities in the field. Both the $12 \mathrm{~m}$ TanDEM$X$ and $5 \mathrm{~m}$ ALOS World 3D had vertical accuracies below $2 \mathrm{~m}$. The $10 \mathrm{~m}$ single-CoSSC TerraSAR-X/TanDEM-X DEMs displayed wide error distributions and some aspect bias, indicating the necessity of stacked scenes for accurate DEM generation (i.e., multiple TanDEM-X pairs).

Having assessed the accuracy of the DEMs, we chose the highest-quality datasets (30 m SRTM-C, 30 and $12 \mathrm{~m}$ TanDEM-X, $10 \mathrm{~m}$ single-CoSSC TerraSAR-X/TanDEM-X, and $5 \mathrm{~m}$ ALOS World 3D) for a geomorphometric analysis of channel profiles and hillslopes in a large $\left(66 \mathrm{~km}^{2}\right)$ catchment with a clear river knickpoint. We show that chi plot analysis of $m / n$ values provides comparable results regardless of DEM resolution or chi plot method when applied to the trunk channel alone in this simple setting. Regarding hillslope analyses, the $5 \mathrm{~m}$ ALOS World 3D $\left(25 \mathrm{~m}^{2}\right.$ per pixel), $10 \mathrm{~m}$ single-CoSSC TerraSAR-X/TanDEM-X $\left(100 \mathrm{~m}^{2}\right), 12 \mathrm{~m}$ TanDEM-X $\left(144 \mathrm{~m}^{2}\right)$, and $30 \mathrm{~m} \mathrm{SRTM-C}$ and TanDEM-X $\left(900 \mathrm{~m}^{2}\right)$ demonstrate similar slopes and characteristic hillslope lengths. The primary difference in geomorphic analysis came in the measurement of curvature, which is shown to be highly resolution (and noise) dependent. Despite low vertical uncertainty, the ALOS World 3D data were found to be excessively noisy in 2-8 pixel steps via a Fourier frequency analysis. This high-frequency, lowwavelength noise is caused by difficulties in optical DEM generation via stereogrammetry, whereas the interferometric radar-derived TanDEM-X DEM had much smoother, more realistic landscape representation with no spurious highfrequency noise.

We demonstrate that the newer generation of 5-12 m DEM products can be useful in assessing hillslope parameters at larger scales and lower costs than lidar but may still be insufficient for fine-scale analysis, for example of hilltop curvatures or channel-head location. Caution should be taken by geomorphologists when using noisy optically generated DEMs, when even single non-stacked radar DEMs (e.g., single-CoSSC TerraSAR-X/TanDEM-X) may provide more realistic landscape representation. DEMs acquired by remote sensing technology onboard satellites are reaching better and higher potential for geomorphic analyses, including landslide detection and identification of smaller-scale features. Despite this improvement, the variability of mountainous landscapes and identification of transient responses in the realm of tectonic geomorphology benefits not only from vertical accuracy but also DEM resolution and the ability to derive higherorder derivatives.

Code availability. Code for discrete Fourier transform analysis of DEM noise is available at https://github.com/bpurinton/DEM_ fourier_noise (Purinton, 2017) and via the Universität Potsdam Remote Sensing and Earth Surface Processes account at https://github. com/UP-RS-ESP.

Data availability. SRTM and ASTER data may be downloaded free of charge at the links in Table 1 . The same is true of the resampled ALOS World 3D $30 \mathrm{~m}$ DEM. The original $5 \mathrm{~m}$ ALOS World 3D DEM, ALOS PRISM optical tri-stereopair, and SPOT6 optical scenes were commercially purchased for this study and cannot be redistributed. Similarly, the TerraSAR-X/TanDEM-X and RapidEye data were received via multiple research proposals, which do not allow data sharing. Finally, the dGPS dataset used in this study is part of ongoing research and therefore unavailable to the public.

\section{The Supplement related to this article is available online at doi:10.5194/esurf-5-211-2017-supplement.}

Author contributions. B. Bookhagen provided field equipment and training as well as financial support and supervision of analysis. B. Purinton carried out analyses, produced figures, and prepared the manuscript under B. Bookhagen's guidance.

Competing interests. The authors declare that they have no conflict of interest.

Acknowledgements. CoSSC TerraSAR-X/TanDEM-X radar data were received through proposal ID XTI_GEOL6727 granted to B. Bookhagen, and TanDEM-X DEMs were received through proposal ID DEM_CALVAL1028 granted to B. Purinton, both from the DLR. RapidEye scenes were received through RapidEye Science Archive (RESA) proposal ID 00195 granted to B. Purinton. The authors thank the DFG Graduate School StRATEGy (IGK2018) and NEXUS funded through the MWFK Brandenburg, Germany. Ricardo Alonso, Manfred Strecker, Lisa Luna, and Patrick Lanouette are thanked for help with field work in March 2015. We particularly thank Kanayim Teshebaeva for help in 
generating the interferometric TerraSAR-X/TanDEM-X DEMs and Wolfgang Schwanghart for development of the terrain analysis toolbox and productive conversations throughout preparation of the paper. Simon Mudd, Stuart Grieve, and the anonymous reviewer are thanked for suggested improvements on the original manuscript.

Edited by: S. Mudd

Reviewed by: S. W. D. Grieve and one anonymous referee

\section{References}

Akaike, H.: A New Look at the Statistical Model Identification, IEEE Trans. Autom. Control, 19, 716-723, doi:10.1109/TAC.1974.1100705, 1974.

Albani, M., Klinkenberg, B., Andison, D. W., and Kimmins, J. P.: The choice of window size in approximating topographic surfaces from Digital Elevation Models, Int. J. Geogr. Inf. Sci., 18, 577-593, 2004.

Allmendinger, R. W., Jordan, T. E., Kay, S. M., and Isacks, B. L.: The Evolution of the Altiplano-Puna Plateau of the Central Andes, Annu. Rev. Earth Pl. Sc., 25, 139-174, 1997.

Arrell, K., Wise, S., Wood, J., and Donoghue, D.: Spectral filtering as a method of visualising and removing striped artefacts in digital elevation data, Earth Surf. Proc. Land., 33, 943-961, 2008.

Athmania, D. and Achour, H.: External Validation of the ASTER GDEM2, GMTED2010 and CGIAR-CSI- SRTM v4.1 Free Access Digital Elevation Models (DEMs) in Tunisia and Algeria, Remote Sensing, 6, 4600-4620, 2014.

Baade, J. and Schmullius, C.: TanDEM-X IDEM precision and accuracy assessment based on a large assembly of differential GNSS measurements in Kruger National Park, South Africa, ISPRS J. Photogramm., 119, 496-508, 2016.

Bagnardi, M., González, P. J., and Hooper, A.: High-resolution digital elevation model from tri-stereo Pleiades-1 satellite imagery for lava flow volume estimates at Fogo Volcano, Geophys. Res. Lett., 43, 6267-6275, 2016.

Becek, K.: Investigation of elevation bias of the SRTM C-and Xband digital elevation models, Int. Arch. Photogramm. Remote Sens. Spatial Inf. Sci., 37, 105-110, 2008.

Berthier, E. and Toutin, T.: SPOT5-HRS digital elevation models and the monitoring of glacier elevation changes in North-West Canada and South-East Alaska, Remote Sens. Environ., 112, 2443-2454, 2008.

Berthier, E., Arnaud, Y., Vincent, C., and Rémy, F.: Biases of SRTM in high-mountain areas: Implications for the monitoring of glacier volume changes, Geophys. Res. Lett., 33, L08502, doi:10.1029/2006GL025862, 2006.

Berthier, E., Arnaud, Y., Kumar, R., Ahmad, S., Wagnon, P., and Chevallier, P.: Remote sensing estimates of glacier mass balances in the Himachal Pradesh (Western Himalaya, India), Remote Sens. Environ., 108, 327-338, 2007.

Bookhagen, B. and Strecker, M. R.: Orographic barriers, high-resolution TRMM rainfall, and relief variations along the eastern Andes, Geophys. Res. Lett., 35, L06403, doi:10.1029/2007GL032011, 2008.

Bookhagen, B. and Strecker, M. R.: Spatiotemporal trends in erosion rates across a pronounced rainfall gradient: Examples from the southern Central Andes, Earth Planet. Sc. Lett., 327-328, 97$110,2012$.
Bookhagen, B., Haselton, K., and Trauth, M. H.: Hydrological modelling of a Pleistocene landslide-dammed lake in the Santa Maria Basin, NW Argentina, Palaeogeogr. Palaeocl., 169, 113-127, 2001.

Booth, A. M., Roering, J. J., and Perron, J. T.: Automated landslide mapping using spectral analysis and high-resolution topographic data: Puget Sound lowlands, Washington, and Portland Hills, Oregon, Geomorphology, 109, 132-147, 2009.

Botev, Z. I., Grotowski, J. F., and Kroese, D. P.: Kernel density estimation via diffusion, Ann. Stat., 38, 2916-2957, 2010.

Burbank, D. W., Leland, J., Fielding, E., Anderson, R. S., Brozovic, N., Reid, M. R., and Duncan, C.: Bedrock incision, rock uplift and threshold hillslopes in the northwestern Himalayas, Nature, 379, 505-510, 1996.

Clubb, F. J., Mudd, S. M., Milodowski, D. T., Hurst, M. D., and Slater, L. J.: Objective extraction of channel heads from highresolution topographic data, Water Resour. Res., 50, 4283-4304, 2014.

Clubb, F. J., Mudd, S. M., Attal, M., Milodowski, D. T., and Grieve, S. W. D.: The relationship between drainage density, erosion rate, and hilltop curvature: Implications for sediment transport processes, J. Geophys. Res.-Earth, 121, 1724-1745, 2016.

DiBiase, R. A., Whipple, K. X., Heimsath, A. M., and Ouimet, W. B.: Landscape form and millennial erosion rates in the San Gabriel Mountains, CA, Earth Planet. Sc. Lett., 289, 134-144, 2010.

DiBiase, R. A., Heimsath, A. M., and Whipple, K. X.: Hillslope response to tectonic forcing in threshold landscapes, Earth Surf. Proc. Land., 37, 855-865, 2012.

Dietrich, W. E., Bellugi, D. G., Sklar, L. S., Stock, J. D., Heimsath, A. M., and Roering, J. J.: Geomorphic Transport Laws for Predicting Landscape form and Dynamics, in: Prediction in Geomorphology, Wiley-Blackwell, Washington, D.C., USA, 103132, 2003.

Du, Y.-N., Feng, G.-C., Li, Z.-W., Zhu, J.-J., and Peng, X.: Generation of high precision DEM from TerraSAR-X/TanDEM-X, Chin. J. Geophys, 58, 1634-1644, 2015.

Farr, T. G., Rosen, P. A., Caro, E., Crippen, R., Duren, R., Hensley, S., Kobrick, M., Paller, M., Rodriguez, E., Roth, L., Seal, D., Shaffer, S., Shimada, J., Umland, J., Werner, M., Oskin, M., Burbank, D., and Alsdorf, D.: The Shuttle Radar Topography Mission, Rev. Geophys., 45, RG2004, doi:10.1029/2005RG000183, 2007.

Fisher, G. B., Bookhagen, B., and Amos, C. B.: Channel planform geometry and slopes from freely available high-spatial resolution imagery and DEM fusion: Implications for channel width scalings, erosion proxies, and fluvial signatures in tectonically active landscapes, Geomorphology, 194, 46-56, 2013.

Fisher, P. F. and Tate, N. J.: Causes and consequences of error in digital elevation models, Prog. Phys. Geog., 30, 467-489, 2006.

Forte, A. M., Whipple, K. X., Bookhagen, B., and Rossi, M. W.: Decoupling of modern shortening rates, climate, and topography in the Caucasus, Earth Planet. Sc. Lett., 449, 282-294, 2016.

Gardelle, J., Berthier, E., and Arnaud, Y.: Impact of resolution and radar penetration on glacier elevation changes computed from DEM differencing, J. Glaciol., 58, 419-422, 2012.

Grieve, S. W. D., Mudd, S. M., and Hurst, M. D.: How long is a hillslope?, Earth Surf. Proc. Land., 41, 1039-1054, 2016 a. 
Grieve, S. W. D., Mudd, S. M., Hurst, M. D., and Milodowski, D. T.: A nondimensional framework for exploring the relief structure of landscapes, Earth Surf. Dynam., 4, 309-325, doi:10.5194/esurf4-309-2016, 2016 b.

Grieve, S. W. D., Mudd, S. M., Milodowski, D. T., Clubb, F. J., and Furbish, D. J.: How does grid-resolution modulate the topographic expression of geomorphic processes?, Earth Surf. Dynam., 4, 627-653, doi:10.5194/esurf-4-627-2016, $2016 \mathrm{c}$.

Harel, M.-A., Mudd, S. M., and Attal, M.: Global analysis of the stream power law parameters based on worldwide ${ }^{10} \mathrm{Be}$ denudation rates, Geomorphology, 268, 184-196, 2016.

Hengl, T.: Finding the right pixel size, Comput. Geosci., 32, 12831298, 2006

Hirano, A., Welch, R., and Lang, H.: Mapping from ASTER stereo image data: DEM validation and accuracy assessment, ISPRS J. Photogramm., 57, 356-370, 2003.

Hofton, M., Dubayah, R., Blair, J. B., and Rabine, D.: Validation of SRTM Elevations Over Vegetated and Non-vegetated Terrain Using Medium Footprint Lidar, Photogramm. Eng. Rem. S., 72, 279-285, 2006.

Höhle, J. and Höhle, M.: Accuracy assessment of digital elevation models by means of robust statistical methods, ISPRS J. Photogramm., 64, 398-406, 2009.

Holzer, N., Vijay, S., Yao, T., Xu, B., Buchroithner, M., and Bolch, T.: Four decades of glacier variations at Muztagh Ata (eastern Pamir): a multi-sensor study including Hexagon KH-9 and Pléiades data, The Cryosphere, 9, 2071-2088, doi:10.5194/tc-92071-2015, 2015.

Hooshyar, M., Wang, D., Kim, S., Medeiros, S. C., and Hagen, S. C.: Valley and channel networks extraction based on local topographic curvature and $\mathrm{k}$-means clustering of contours, Water Resour. Res., 52, 8081-8102, 2016.

Howard, A. D., Dietrich, W. E., and Seidl, M. A.: Modeling fluvial erosion on regional to continental scales, J. Geophys. Res.-Sol. Ea., 99, 13971-13986, 1994.

Hurst, M. D., Mudd, S. M., Walcott, R., Attal, M., and Yoo, K.: Using hilltop curvature to derive the spatial distribution of erosion rates, J. Geophys. Res.-Earth, 117, F02017, doi:10.1029/2011JF002057, 2012.

Hurvich, C. M. and Tsai, C.-H.: Regression and time series model selection in small samples, Biometrika, 76, 297-307, 1989.

Ijjasz-Vasquez, E. J. and Bras, R. L.: Scaling regimes of local slope versus contributing area in digital elevation models, Geomorphology, 12, 299-311, 1995.

Jaber, W. A., Floricioiu, D., Rott, H., and Eineder, M.: Surface elevation changes of glaciers derived from SRTM and TanDEM-X DEM differences, in: 2013 IEEE International Geoscience and Remote Sensing Symposium - IGARSS, 21-26 July 2013, Melbourne, Australia, IEEE, 1893-1896, doi:10.1109/IGARSS.2013.6723173, 2013.

Jarvis, A., Reuter, H. I., Nelson, A., and Guevara, E.: Holefilled SRTM for the globe Version 4, CGIAR-CSI SRTM $90 \mathrm{~m}$ Database, available at: http://srtm.csi.cgiar.org (last access: 1 September 2016), 2008.

Kääb, A.: Combination of SRTM3 and repeat ASTER data for deriving alpine glacier flow velocities in the Bhutan Himalaya, Remote Sens. Environ., 94, 463-474, 2005.
Kervyn, M., Ernst, G. G. J., Goossens, R., and Jacobs, P.: Mapping volcano topography with remote sensing: ASTER vs. SRTM, Int J. Remote Sens., 29, 6515-6538, 2008.

Kirby, E. and Whipple, K. X.: Expression of active tectonics in erosional landscapes, J. Struct. Geol., 44, 54-75, 2012.

Kolecka, N. and Kozak, J.: Assessment of the Accuracy of SRTM C- and X-Band High Mountain Elevation Data: a Case Study of the Polish Tatra Mountains, Pure Appl. Geophys., 171, 897-912, 2014.

Lague, D.: The stream power river incision model: evidence, theory and beyond, Earth Surf. Proc. Land., 39, 38-61, 2014.

Li, Z.: On the measure of digital terrain model accuracy, Photogramm. Rec., 12, 873-877, 1988.

Liu, Z., Peng, M., and Di, K.: A continuative variable resolution digital elevation model for ground-based photogrammetry, Comput. Geosci., 79, 71-79, 2014.

Luna, L. V., Bookhagen, B., Niedermann, S., Rugel, G., Scharf, A., and Merchel, S.: Glacial chronology and production rate crosscalibration of six cosmogenic nuclide/mineral systems from the central southern Andean Plateau (Puna, 24 S, 4000-5000 m), Earth Planet. Sc. Lett., in review, 2017.

Massey, F. J.: The Kolmogorov-Smirnov Test for Goodness of Fit, J. Am. Stat. Assoc., 46, 68-78, 1951.

METI/NASA/USGS: ASTER Global DEM Validation Summary Report, Tech. rep., METI/ERSDAC, NASA/LPDAAC, USGS/EROS, available at: https://lpdaac.usgs.gov/sites/default/ files/public/aster/docs/ASTER_GDEM_Validation_Summary_ Report.pdf (last access: 12 April 2017), 2009.

Montgomery, D. R. and Foufoula-Georgiou, E.: Channel network source representation using digital elevation models, Water Resour. Res., 29, 3925-3934, 1993.

Montgomery, D. R., Balco, G., and Willett, S. D.: Climate, tectonics, and the morphology of the Andes, Geology, 29, 579-579, 2001.

Mudd, S. M., Attal, M., Milodowski, D. T., Grieve, S. W. D., and Valters, D. A.: A statistical framework to quantify spatial variation in channel gradients using the integral method of channel profile analysis, J. Geophys. Res.-Earth, 119, 138-152, 2014.

Mukherjee, S., Joshi, P. K., Mukherjee, S., Ghosh, A., Garg, R. D., and Mukhopadhyay, A.: Evaluation of vertical accuracy of open source Digital Elevation Model (DEM), Int. J. Appl. Earth Obs., 21, 205-217, 2013.

Neckel, N., Braun, A., Kropácek, J., and Hochschild, V.: Recent mass balance of the Purogangri Ice Cap, central Tibetan Plateau, by means of differential X-band SAR interferometry, The Cryosphere, 7, 1623-1633, doi:10.5194/tc-7-1623-2013, 2013.

Neelmeijer, J., Motagh, M., and Bookhagen, B.: High-Resolution Digital Elevation Models from Single-Pass TanDEM-X Imagery Over Mountainous Regions: A Case Study for Inylchek Glacier, Central Asia, ISPRS J. Phtogramm., in review, 2017.

Nuth, C. and Kääb, A.: Co-registration and bias corrections of satellite elevation data sets for quantifying glacier thickness change, The Cryosphere, 5, 271-290, doi:10.5194/tc-5-271-2011, 2011.

Olen, S. M., Bookhagen, B., and Strecker, M. R.: Role of climate and vegetation density in modulating denudation rates in the $\mathrm{Hi}-$ malaya, Earth Planet. Sc. Lett., 445, 57-67, 2016. 
Ouimet, W. B., Whipple, K. X., and Granger, D. E.: Beyond threshold hillslopes: Channel adjustment to base-level fall in tectonically active mountain ranges, Geology, 37, 579-582, 2009.

Pandey, P. and Venkataraman, G.: Comparison of DEMs derived from TanDEM-X and SRTM-C for Himalayan terrain, in: 2013 IEEE International Geoscience and Remote Sensing Symposium - IGARSS, 21-26 July 2013, Melbourne, Australia, IEEE, 322325, doi:10.1109/IGARSS.2013.6721157, 2013.

Passalacqua, P., Tarolli, P., and Foufoula-Georgiou, E.: Testing space-scale methodologies for automatic geomorphic feature extraction from lidar in a complex mountainous landscape, Water Resour. Res., 46, W11535, doi:10.1029/2009WR008812, 2010a.

Passalacqua, P., Trung, T. D., Foufoula-Georgiou, E., Sapiro, G., and Dietrich, W. E.: A geometric framework for channel network extraction from lidar: Nonlinear diffusion and geodesic paths, J. Geophys. Res.-Earth, 115, F01002, doi:10.1029/2009JF001254, 2010b.

Passalacqua, P., Belmont, P., Staley, D. M., Simley, J. D., Arrowsmith, J. R., Bode, C. A., Crosby, C., DeLong, S. B., Glenn, N. F., Kelly, S. A., Lague, D., Sangireddy, H., Schaffrath, K., Tarboton, D. G., Wasklewicz, T., and Wheaton, J. M.: Analyzing high resolution topography for advancing the understanding of mass and energy transfer through landscapes: A review, EarthSci. Rev., 148, 174-193, 2015.

Paul, F. and Haeberli, W.: Spatial variability of glacier elevation changes in the Swiss Alps obtained from two digital elevation models, Geophys. Res. Lett., 35, L21502, doi:10.1029/2008GL034718, 2008.

Perron, J. T. and Royden, L.: An integral approach to bedrock river profile analysis, Earth Surf. Proc. Land., 38, 570-576, 2013.

Perron, J. T., Kirchner, J. W., and Dietrich, W. E.: Spectral signatures of characteristic spatial scales and nonfractal structure in landscapes, J. Geophys. Res., 113, F04003, doi:10.1029/2007JF000866, 2008.

Perroy, R. L., Bookhagen, B., Asner, G. P., and Chadwick, O. A.: Comparison of gully erosion estimates using airborne and ground-based LiDAR on Santa Cruz Island, California, Geomorphology, 118, 288-300, 2010.

Pike, R. J., Evans, I. S., and Hengl, T.: Geomorphometry: A Brief Guide, chap. 1, in: Geomorphometry: Concepts, Software, Applications, edited by: Hengl, T. and Reuter, H. I., Elsevier, Amsterdam, the Netherlands, 3-30, doi:10.1016/S01662481(08)00001-9, 2009.

Pipaud, I., Loibl, D., and Lehmkuhl, F.: Evaluation of TanDEM-X elevation data for geomorphological mapping and interpretation in high mountain environments - A case study from SE Tibet, China, Geomorphology, 246, 232-254, 2015.

Priestley, M. B.: Spectral Analysis and Time Series, Academic Press, New York, USA, 1981.

Purinton, B.: DEM Fourier noise analysis code for MATLAB, GitHub repository, available at: https:/github.com/bpurinton/ DEM_fourier_noise and https://github.com/UP-RS-ESP, last access: 14 January 2017.

Raaflaub, L. D. and Collins, M. J.: The effect of error in gridded digital elevation models on the estimation of topographic parameters, Environ. Modell. Softw., 21, 710-732, 2006.

Racoviteanu, A. E., Manley, W. F., Arnaud, Y., and Williams, M. W.: Evaluating digital elevation models for glaciologic appli- cations: An example from Nevado Coropuna, Peruvian Andes, Global Planet. Change, 59, 110-125, 2007.

Rankl, M. and Braun, M.: Glacier elevation and mass changes over the central Karakoram region estimated from TanDEM-X and SRTM/X-SAR digital elevation models, Ann. Glaciol., 57, 273281, 2016.

Reuter, H. I., Hengl, T., Gessler, P., and Soille, P.: Preparation of DEMs for Geomorphometric Analysis, chap. 4, in: Geomorphometry: Concepts, Software, and Applications, edited by: Hengl, T. and Reuter, H. I., Elsevier, Amsterdam, the Netherlands, 87-120, doi:10.1016/S0166-2481(08)00004-4, 2009.

Rexer, M. and Hirt, C.: Comparison of free high resolution digital elevation data sets (ASTER GDEM2, SRTM v2.1/v4.1) and validation against accurate heights from the Australian National Gravity Database, Aust. J. Earth Sci., 61, 213-226, 2014.

Rignot, E., Echelmeyer, K., and Krabill, W.: Penetration depth of interferometric synthetic-aperture radar signals in snow and ice, Geophys. Res. Lett., 28, 3501-3504, 2001.

Rodriguez, E., Morris, C. S., and Belz, J. E.: A Global Assessment of the SRTM Performance, Photogramm. Eng. Rem. S., 72, 249260, 2006.

Roering, J. J., Kirchner, J. W., and Dietrich, W. E.: Evidence for nonlinear, diffusive sediment transport on hillslopes and implications for landscape morphology, Water Resour. Res., 35, 853870, 1999.

Roering, J. J., Perron, J. T., and Kirchner, J. W.: Hillslope morphology and functional relationships between topographic relief and denudation, Earth Planet. Sc. Lett., 264, 245-258, doi:10.1016/j.eps1.2007.09.035, 2007.

Roering, J. J., Marshall, J., Booth, A. M., Mort, M., and Jin, Q.: Evidence for biotic controls on topography and soil production, Earth Planet. Sc. Lett., 298, 183-190, 2010.

Roering, J. J., Mackey, B. H., Marshall, J. A., Sweeney, K. E., Deligne, N. I., Booth, A. M., Handwerger, A. L., and CerovskiDarriau, C.: "You are HERE": Connecting the dots with airborne lidar for geomorphic fieldwork, Geomorphology, 200, 172-183, 2013.

Rohrmann, A., Strecker, M. R., Bookhagen, B., Mulch, A., Sachse, D., Pingel, H., Alonso, R. N., Schildgen, T. F., and Montero, C.: Can stable isotopes ride out the storms? The role of convection for water isotopes in models, records, and paleoaltimetry studies in the central Andes, Earth Planet. Sc. Lett., 407, 187-195, 2014.

Rossi, C., Minet, C., Fritz, T., Eineder, M., and Bamler, R.: Temporal monitoring of subglacial volcanoes with TanDEM-X - Application to the 2014-2015 eruption within the Bárðarbunga volcanic system, Iceland, Remote Sens. Environ., 181, 186-197, 2016.

Scherler, D., Bookhagen, B., Wulf, H., Preusser, F., and Strecker, M. R.: Increased late Pleistocene erosion rates during fluvial aggradation in the Garhwal Himalaya, northern India, Earth Planet. Sc. Lett., 428, 255-266, 2015.

Schwanghart, W. and Scherler, D.: Short Communication: TopoToolbox 2 - MATLAB-based software for topographic analysis and modeling in Earth surface sciences, Earth Surf. Dynam., 2, 1-7, doi:10.5194/esurf-2-1-2014, 2014.

Shelef, E. and Hilley, G. E.: Impact of flow routing on catchment area calculations, slope estimates, and numerical simulations of landscape development, J. Geophys. Res.-Earth, 118, 21052123, 2013. 
Shortridge, A. and Messina, J.: Spatial structure and landscape associations of SRTM error, Remote Sens. Environ., 115, 1576-1587, 2011.

Smith, B. and Sandwell, D.: Accuracy and resolution of shuttle radar topography mission data, Geophys. Res. Lett., 30, 1467, doi:10.1029/2002GL016643, 2003.

Snyder, N. P., Whipple, K. X., Tucker, G. E., and Merritts, D. J.: Landscape response to tectonic forcing: Digital elevation model analysis of stream profiles in the Mendocino triple junction region, northern California, Geol. Soc. Am. Bull., 112, 1250-1263, 2000.

Sofia, G., Pirotti, F., and Tarolli, P.: Variations in multiscale curvature distribution and signatures of LiDAR DTM errors, Earth Surf. Proc. Land., 38, 1116-1134, 2013.

Sofia, G., Hillier, J. K., and Conway, S. J.: Frontiers in Geomorphometry and Earth Surface Dynamics: possibilities, limitations and perspectives, Earth Surf. Dynam., 4, 721-725, doi:10.5194/esurf-4-721-2016, 2016.

Tachikawa, T., Kaku, M., Iwasaki, A., Gesch, D., Oimoen, M., Zhang, Z., Danielson, J., Krieger, T., Curtis, B., Haase, J., Abrams, M., Crippen, R., and Carabajal, C.: ASTER Global Digital Elevation Model Version 2 - Summary of Validation Results, Tech. rep., Joint Japan-US ASTER Science Team, available at: http://www.jspacesystems.or.jp/ersdac/GDEM/ ver2Validation/Summary_GDEM2_validation_report_final.pdf (last access: 12 April 2017), 2011.

Tadono, T., Ishida, H., Oda, F., Naito, S., Minakawa, K., and Iwamoto, H.: Precise Global DEM Generation by ALOS PRISM, ISPRS Ann. Photogramm. Remote Sens. Spatial Inf. Sci., II-4, 71-76, 2014.

Tarboton, D. G.: Terrain analysis using digital elevation models (TauDEM), Utah State University, Logan, USA, 2005.

Tarboton, D. G., Bras, R. L., and Rodriguez-Iturbe, I.: On the extraction of channel networks from digital elevation data, Hydrological Processes, 5, 81-100, 1991.

Tarolli, P.: High-resolution topography for understanding Earth surface processes: Opportunities and challenges, Geomorphology, 216, 295-312, 2014.

Tarolli, P. and Dalla Fontana, G.: Hillslope-to-valley transition morphology: New opportunities from high resolution DTMs, Geomorphology, 113, 47-56, 2009.

Tarolli, P. and Tarboton, D. G.: A new method for determination of most likely landslide initiation points and the evaluation of digital terrain model scale in terrain stability mapping, Hydrol. Earth Syst. Sci., 10, 663-677, doi:10.5194/hess-10-663-2006, 2006.
Toutin, T. and Cheng, P.: DEM generation with ASTER stereo data, Earth Observation Magazine, 10, 10-13, 2001.

Trauth, M. H., Alonso, R. A., Haselton, K. R., Hermanns, R. L., and Strecker, M. R.: Climate change and mass movements in the NW Argentine Andes, Earth Planet. Sc. Lett., 179, 243-256, 2000.

Tseng, C.-M., Lin, C.-W., Fontana, G. D., and Tarolli, P.: The topographic signature of a major typhoon, Earth Surf. Proc. Land., 40, 1129-1136, 2015.

Van Niel, T. G., McVicar, T. R., Li, L., Gallant, J. C., and Yang, Q.: The impact of misregistration on SRTM and DEM image differences, Remote Sens. Environ., 112, 2430-2442, 2008.

Vaze, J., Teng, J., and Spencer, G.: Impact of DEM accuracy and resolution on topographic indices, Environ. Modell. Softw., 25, 1086-1098, 2010.

Wechsler, S. P.: Uncertainties associated with digital elevation models for hydrologic applications: a review, Hydrol. Earth Syst. Sci., 11, 1481-1500, doi:10.5194/hess-11-1481-2007, 2007.

Wessel, B.: TanDEM-X Ground Segment - DEM Products Specification Document, EOC, DLR, Oberpfaffenhofen, Germany, Public Document TD-GS-PS-0021, Issue 3.1, available at: https: //tandemx-science.dlr.de/, last access: 1 December 2016.

Whipple, K. X. and Tucker, G. E.: Dynamics of the stream-power river incision model: Implications for height limits of mountain ranges, landscape response timescales, and research needs, J. Geophys. Res.-Sol. Ea., 104, 17661-17674, 1999.

Wiener, N.: Extrapolation, interpolation, and smoothing of stationary time series, vol. 7, MIT press, Cambridge, MA, USA, 1949.

Wilson, J. P.: Digital terrain modeling, Geomorphology, 137, 107121, 2012.

Wobus, C., Whipple, K. X., Kirby, E., Snyder, N., Johnson, J., Spyropolou, K., Crosby, B., and Sheehan, D.: Tectonics from topography: procedures, promise, and pitfalls, in: Tectonics, Climate, and Landscape Evolution, edited by: Willett, S. D., Hovius, N., Brandon, M. T., and Fisher, D. M., Geological Society of America Special Paper, 398, 55-74, doi:10.1130/2006.2398(04), 2006.

Zhang, W. and Montgomery, D. R.: Digital elevation model grid size, landscape representation, and hydrologic simulations, Water Resour. Res., 30, 1019-1028, 1994. 